\title{
LA CIENCIA CLIMÁTICA EN EL SIGLO XVII: LA APORTACIÓN DE VARENIO EN LA GEOGRAFÍA GENERAL ${ }^{1}$
}

Jorge Olcina Cantos

Universidad de Alicante

\section{RESUMEN}

La disciplina climática experimenta notables avances en el siglo XVII en una época de importantes mejoras en la ciencia y en el pensamiento. El siglo XVII, en efecto, es el siglo de la aparición de los aparatos de medida de los elementos climáticos, que se irán perfeccionando en los siglos posteriores. Pero es, también, el siglo de aparición de nuevas propuestas de explicación de la circulación de los vientos y de los movimientos atmosféricos a gran escala. En este contexto, la publicación de la Geografía General de Bernhardus Varenius representa un avance principal para la consolidación de la geografía como disciplina científica y, en sus páginas, podemos encontrar además explicaciones sobre cuatro aspectos climáticos de interés: la composición de la atmósfera, causa del clima terrestre y características del aire; las causas, tipos y características de los vientos; los fenómenos ópticos y otros elementos climáticos, y la existencia de zonas térmicas y klimata en la esfera terrestre.

Palabras clave: Revolución científica, climatología, siglo XVII, Varenio, Geografía General

\section{ABSTRACT}

Climatology in the seventeenth century: Varenius 'contribution in his General Geography

Climate science advances significantly in the seventeenth century, at a time of substantial improvements in science and philosophy. The seventeenth century is indeed the century of the development of measuring equipment of the climatic elements, which will

1. Este trabajo forma parte de las investigaciones llevadas a cabo en el seno del grupo de investigación en «Historia y Clima» de la Universidad de Alicante, bajo dirección del prof. Armando Alberola Romá, desarrolladas en el marco del proyecto I+D (HAR2013-44972-P). 
be refined in the following centuries. But it is also the century of development of new proposals to explain the circulation of winds and large-scale atmospheric motions. In this context, the publication of the General Geography by Bernhardus Varenius, represents a major advance for the consolidation of geography as a scientific discipline and in its pages we can find explanations on four climate areas of interest: the composition of the atmosphere and the causes the Earth's climate; the causes, types and characteristics of terrestrial winds; optical phenomena and other climate elements, and the existence of thermal zones and klimata in the terrestrial sphere.

Keywords: Scientific revolution, climatology, seventeenth century, Varenius, General Geography.

\section{LA REVOLUCIÓN CIENTÍFICA DEL S. XVII Y SU INFLUENCIA EN LA CLIMATOLOGÍA}

El siglo XVII es el siglo de la revolución científica, o mejor, de las pequeñas revoluciones en diversos campos de las ciencias que culminan con las decisivas aportaciones de Descartes y Newton. Se mejoran medios de observación y análisis de los fenómenos naturales y avanzan de manera determinante los métodos científicos en la búsqueda de respuestas a procesos físicos y naturales que superasen el providencialismo dominante. La apuesta renacentista por el ser humano se irá consolidando en el siglo XVII y culminará con el racionalismo ilustrado del XVIII. La propia expresión «revolución científica» para denominar a este período de aportaciones científicas fundamentales ocurridas en el momento central de la Edad Moderna se pone en entredicho al comprobar que estos avances se suceden en el tiempo, entre los siglos XVI y XVIII, sin suponer rupturas radicales sino continua suma de mejoras (Redondo Álvaro, 2008).

No obstante, el siglo XVII queda encerrado, en la explicación histórica de los avances científicos y culturales, entre el renacimiento y la ilustración, a modo de período bisagra en el que no llega a valorarse, como se debe, la importancia de las aportaciones llevadas a cabo en esos años. Es una especie de siglo maldito, en expresión de Parker (2014), donde los avatares políticos y militares no permiten contemplar la excelencia de las reflexiones para el avance científico que se producen en este período.

Se desarrolla el empirismo, con las aportaciones de Bacon y Hume, que defenderán la experiencia sensorial como fundamento del conocimiento. Sólo son reales los objetos y fenómenos particulares y la razón puede ordenarlos y obtener conclusiones inductivas a partir de ellos. Las ideas, para el empirismo, son copias de las impresiones. Por su parte, Descartes defenderá, en el marco del racionalismo, que sólo la ordenación lógica del mundo que otorga el pensamiento permite comprender la realidad y establecer principios deductivos. Para ello, se potencia el método matemático de deducir a partir de unos pocos pero incontestables axiomas. Descartes defenderá la necesidad de la certeza 
mediante el uso de la duda y para ello debe partirse, según el filósofo francés, de realidades muy simples, a modo de verdades sobre las que no se pueda dudar, que sirven como punto de partida para la obtención de verdades más complejas (duda metódica).

Desde la física, Newton es la gran figura de este período. La mecánica de Newton se convertirá en el modelo de lo que debía ser la teoría científica y tendrá efectos en la obra de científicos y filósofos posteriores. Es interesante destacar la relación de Newton con la geografia, puesto que llegará a ser el editor de varias ediciones de la Geografía General de Varenio en su condición de «profesor Lucasiano» de la Universidad de Cambridge. Y ello se vincula a la propia idea de espacio como realidad absoluta capaz de ser medida del físico inglés. La geografía interesa a Newton por ser una disciplina que se ocupa del estudio de la superficie terrestre en su magnitud física de posición en el espacio y donde es posible la aplicación de procedimientos de la matemática y la física en la explicación de los fenómenos terrestres.

En relación con la evolución de la geografía en el siglo XVII y la aportación básica en este momento que representa la obra de Varenio, hay que recordar que mientras Descartes, con su racionalismo si influyo de forma directa en la obra de Varenio, Newton no pudo influir en la obra del geógrafo alemán porque nació pocos años antes de la muerte de Varenio. Por el contrario será Varenio el que influirá en Newton, como se ha señalado, hasta el punto de que el físico inglés editará la Geografía General aportando notas y comentario propios. Newton es el exponente de la culminación de las ideas de la revolución científica que se había ido generando desde el Renacimiento, con Copérnico, Kepler y Galileo y que pondrán fin a la dependencia de las ideas de la filosofía de la naturaleza de Aristóteles o Plinio, con la defensa del heliocentrismo como aspecto de ruptura más destacado.

Esta «revolución» en la manera de entender y explicar los fenómenos de la naturaleza y en los métodos de medición que precisarán de aparatos que se idean y construyen ex profeso, tendrá efecto en las disciplinas atmosférica y climática que experimentarán un impulso decisivo para su consolidación como ciencia.

El siglo XVII, en efecto, es el siglo de la aparición de los aparatos de medida de los elementos climáticos, que se irán perfeccionando en los siglos posteriores. Pero es ahora cuando se sientan las bases de lo que a partir del s. XIX se denominará climatología analítica o ciencia climática basada en el tratamiento de datos. En este sentido, debe destacarse la labor de Galileo Galilei, considerado como el fundador del método experimental y al que se le atribuye la construcción del primer termómetro científico, denominado termoscopio neumático, en 1607, que permitirá la medición de temperaturas en un rango de 18 a $26{ }^{\circ} \mathrm{C}$. En 1639, Benedetto Castelli idea un primer pluviómetro que será perfeccionado en 1662 por Christopher Wren con un sistema de cubetas basculantes y mejorado 
en 1670 por Robert Hooke. En 1641, Fernando II, Gran Duque de Toscana, construye el termómetro de bulbo de alcohol con capilar sellado; el instrumento estaba provisto de un tuvo de vidrio con alcohol marcado con 50 grados, pero no utilizó el cero como un punto fijo. Por su parte, en 1644, tras llevar a cabo su famoso experimento, Torricelli construye el primer barómetro de mercurio. El primer higrómetro nació de la inventiva del físico francés Guillaume Amontons que lo presentaría en 1687 en la Academia de Ciencias francesa. Por último, el primer anemómetro para la medida de la velocidad del viento lo construye en 1667 Robert Hooke. De manera que, a finales del siglo XVII, se dispone del aparataje básico para la medición de los elementos climáticos principales.

La puesta a punto de este instrumental meteorológico permitirá el desarrollo de los primeros embriones de redes meteorológicas. La primera de ellas, integrada por una decena de observatorios, fue instalada, a instancias del Gran Duque Fernando II de Toscana, por Luigi Antinori y funcionó entre 1654 y 1667. Será el germen de otras redes de observación que se irán ampliando y consolidando en los siguientes siglos.

En el estudio de los elementos atmosféricos, la medida de la presión atmosférica fue, sin duda, uno de los problemas importantes que tuvo que abordar la ciencia en el siglo XVII. Desde la época de Aristóteles habían perdurado dos ideas erróneas y generalmente admitidas. La primera de ella era que el aire no pesaba y la segunda que no existía el vacío. Galileo rechazará ambas cuestiones y demostrará, mediante una serie de experimentos, que el aire pesa. En 1643 Torricelli llevó a cabo el famoso experimento realizado en su laboratorio, llenando de mercurio un tubo de 1 metro de largo, (cerrado por uno de los extremos). Invirtió dicho tubo sobre una cubeta llena de mercurio, de inmediato la columna de mercurio descendió hasta una altura de 76 centímetros $(760 \mathrm{~mm})$. Torricelli interpretó que a esa altura se producía la influencia de la presión atmosférica. La comprobación en campo de este hecho la realizó, unos años después, en 1648, Florin Périer, por encargo de su cuñado Blaise Pascal, al medir la altura de una columna de mercurio a tres altitudes diferentes, durante su ascenso al Puy de Dome. En este experimento se demostró que la presión atmosférica decrecía con el incremento de altitud, si bien ese descenso resultaba cada vez menos rápido.

En 1656, el alemán Otto von Guericke demostraría la existencia del vacío con su célebre experimento de los hemisferios de Magdeburgo, señalando que la presión atmosférica equivalía a un peso muy considerable. El experimento consistía en tratar de separar dos hemisferios metálicos, de unos $50 \mathrm{~cm}$ de diámetro, unidos entre sí por simple contacto, formando una esfera herméticamente cerrada, de la que se extraía el aire con una bomba de vacío, por cierto, inventada por el propio von Guericke. Para facilitar el cierre hermético de las semiesferas metálicas se disponía de un aro de cuero que se colocaba entre las superficies que se tocaban. Cada hemisferio disponía de varias argollas para pasar cuerdas 
o cadenas por ellas y así poder tirar hacia los lados opuestos. En los hemisferios solo actúa la presión atmosférica puesto que al extraer el aire no hay presión en el interior. El aire atmosférico ejerce presión sobre los hemisferios y, si la superficie de los mismos sobre la que actúa la presión es suficientemente grande, se necesita una fuerza bastante considerable para separarlos.

En el siglo XVII se formulan, asimismo, un conjunto de leyes físicas de la máxima trascendencia, como la de los gases o Ley de Boyle, formulada de forma independiente por el físico irlandés Robert Boyle en 1662 y por el físico y botánico francés Edme Mariotte, en 1676, según la cual a temperatura constante el volumen de una masa de gas es inversamente proporcional a la presión ejercida. Newton enunciaría en sus Philosophiae Naturalis Principia Mathematica (1687) las famosas tres leyes del movimiento (inercia, aceleración y acción/ reacción) que resultarán básicas para comprender el desplazamiento de los vientos en la superficie terrestre y, en especial, su segunda ley (ley de la aceleración) según la cual el movimiento de un cuerpo cambia bajo la acción de una fuerza al experimentar una aceleración en la misma dirección de la fuerza.

Es interesante, asimismo, señalar los hallazgos relacionados con la luz y los fenómenos ópticos, puesto que tendrán influencia en la explicación que diferentes autores -entre ellos el propio Varenio- darán a estos fenómenos en la atmósfera en la propia centuria del seiscientos y en los siglos posteriores. Así, Descartes establecerá la ley de la refracción de la luz, estudiará también los espejos esféricos y las lentes y en su ensayo sobre Los Meteoros formulará una teoría para explicar la formación del arco iris. En 1672, Newton propondrá la teoría corpuscular de la luz que junto a otras ideas y principios del físico inglés sobre la luz serán la base de su obra capital en esta cuestión, Optiks (1704). Unos años después, en 1678, Cristiaan Huygens dará un paso más en la explicación del fenómeno con su teoría ondulatoria.

Un tema principal para la filosofía natural y la física durante el siglo XVII fue el viento. No en vano, como señala, Pelkowsky (2006) en este siglo se consolida la «pneumática»o arte creado en el período helenístico, encargado de estudiar la naturaleza, el peso, y la presión del aire y sus efectos. Inicialmente organizada en torno a dos innovaciones instrumentales ocurridas en este período (el tubo de Torricelli y la bomba de vacío), irá ampliando su campo de estudio en la centuria siguiente e incorporando el análisis del termómetro, los fenómenos térmicos y meteorológicos, el estudio y la naturaleza del sonido y hasta los tipos y las características de los vientos. La Enciclopedia Británica incluiría la voz «pneumática» en su primera edición de 1768, con la explicación de todos estos aspectos, pero con estudio detallado de las cuestiones relativas al viento.

El origen del viento y sus movimientos movieron un intenso debate de propuestas entre los filósofos y físicos de la época, que deseaban superar las ideas aristotélicas sobre este elemento climático. Recordemos que Aristóteles, en Los 
Meteorológicos (S. IV a.C) relacionaba los fenómenos atmosféricos con la actividad del Sol que originaba dos tipos de «exhalaciones»: una caliente y seca producida por el fuego que se levanta de la tierra; otra caliente y húmeda (vapor) producida por el agua la cual se levantaba de la parte acuosa de la tierra. La exhalación húmeda no se da sin la seca, ni la seca sin la húmeda. Los diferentes meteoros eran formados por ellas. Las «evaporaciones» sufrían transformaciones debido a los cambios de temperatura, a la variación del calor del suelo por la proximidad a la esfera de fuego. De la «evaporación» seca se producía el trueno, el rayo, los vientos, los terremotos, los cometas y otros fenómenos ardientes. Del «vapor» húmedo se desarrollaban las nubes, la lluvia, la nieve, el granizo, la niebla, el rocío y las heladas (Libro II, cap. 4). Para Aristóteles la causa del viento es clara: «El sol hace cesar e impulsa a los vientos. Consumiendo la exhalación los hace cesar y con la rapidez de la desecación impide que se formen» (Libro II, cap. 5). Aristóteles otorga a la zona tórrida el rasgo de ser una región principal de producción de vientos del sur hacia el norte debido a la cercanía del sol e incluso señala que dado que «esa región es mucho más amplia y más abierta, el viento del sur es más grande, más fuerte y más cálido que el del norte; y llega más aquí que éste allí» (Libro II, cap. 5). Este aspecto que es causa, además, de la inahabitabilidad de la región torrida, será rechazado a partir del siglo $\mathrm{XV}$ y, especialmente, en el siglo XVI, tras el descubrimiento del Nuevo Mundo y la constatación de la existencia de vida humana en la zona tórrida del planeta. Así lo manifestarán varios Cronístas de Indias en sus escritos y, particularmente, el padre Acosta en su Historia Natural y Moral de las Indias (Olcina Cantos, 2014).

Tras las críticas a las ideas aristotélicas sobre los vientos en el siglo XVI, será Francis Bacon, en la centuria siguiente, el que rechace de manera más intensa los argumentos clásicos sobre el funcionamiento de los vientos en sus reflexiones sobre filosofía natural. En su Historia Natural y Experimental de los vientos (1622), Bacon ofrece una nueva explicación para entender el funcionamiento de los vientos generales, en esencia los vientos constantes del ámbito intertropical: «Hay pocos fenómenos observados sobre los vientos generales; no es sorprendente, ya que estos vientos se encuentran principalmente dentro de los trópicos, donde precipuamente se encuentran los lugares condenados por las antiguos por inhabitables. [...] Es un hecho cierto que un viento constante de Este a Oeste, llamado «Brisa» por los navegantes, sopla constantemente entre los trópicos; pero su causa es dudosa. Puede ser debida a esto: que el aire, como habíamos notado previamente, se mueve en la dirección de los cielos, aunque menos perceptiblemente fuera de los trópicos, a raíz de los menores círculos allí, mientras que es evidente dentro de ellos, donde los círculos son más grandes. Otra razón puede ser ésta: que todo aire es dilatado por el calor, y, debido a esta dilatación no puede ser contenido en el mismo espacio, el aire contiguo es forzosamente 
impulsado, de tal forma que crea la brisa constante; mientras que el sol mantiene su curso. Pero esta dilatación ha de ser más considerable dentro de los trópicos, donde el sol tiene mayor poder; fuera de ellos, es apenas imperceptible».

Un aspecto importante en la deducción de Bacon es determinar si estas «brisas» se producen por la noche puesto que la rotación del aire continua por la noche pero el calor del sol no. Al respecto, señala que «es seguro que esta brisa no sopla durante la noche, pero sí en la mañana y algún tiempo después del amanecer». Y sobre la trayectoria de esta «brisa» indica que «si el aire participa en el movimiento del cielo, no sólo que el viento del este es concurrente con el movimiento del aire, y el viento del oeste se opone a ello»...Y concluye: «La brisa constante de que hablamos (que puede ser un movimiento del aire) no es del este, sino del nordeste». Bacon otorga, por tanto, un papel importante al movimiento del Sol en la explicación de la propia trayectoria de los vientos y a los procesos de dilatación que experimenta el aire calentado por la radiación solar como causa del movimiento inicial ${ }^{2}$.

Como se aprecia, la búsqueda de la causa última del movimiento de los vientos tenía por objeto principal, en el siglo XVII, la explicación de los vientos constantes del ámbito intertropical (alisios) que recibían, por lo común, la denominación de «brisa» constante.

En relación con esta cuestión es necesario referirse a la formulación de la primera visión de conjunto sobre la circulación atmosférica general que tiene argumento principal en el funcionamiento de dicha circulación en el ámbito intertropical. Este esquema se debe al prestigioso científico inglés Edmund Halley. En un artículo de 1686, básico en la historia de la ciencia climática ${ }^{3}$, el sabio inglés indaga sobre la causa última de los vientos alisios (trade-winds) y de los monzones. Realiza una descripción exhaustiva de las áreas planetarias donde soplan estos vientos principales de la circulación atmosférica sobre la superficie terrestre y de los rasgos estacionales de los mismos. Esboza el primer mapa de vientos del ámbito intertropical indicando la dirección de soplo de ambos vientos regulares (vid. Figura 1).

Halley indaga en su ensayo la causa última que origina el movimiento y dirección de estos vientos y afirma que frente a otros autores que indican la importancia de la rotación terrestre en la explicación del soplo de los alisios y los monzones, la verdadera fuente o fuerza motriz que origina estos vientos

2. El Tratado sobre los vientos de Francis Bacon, de 1622, es un ensayo detallado sobre este elemento climático que incluye una clasificación de vientos y su explicación causal, contrastando las opiniones expresadas por autores clásico (Aristóteles y Plinio el Viejo) y modernos (José de Acosta). Puede consultarse on line: http://www.sirbacon.org/naturalhistorywinds.htm

3. Vid. Halley, E. «An Historial Account of the Trade Winds, and Monsoons, observable in the Seas between and near the Tropicks, with an attempt to assing the phisical cause of the said winds», Philosophical Transactions, n. ${ }^{\circ} 183$. 


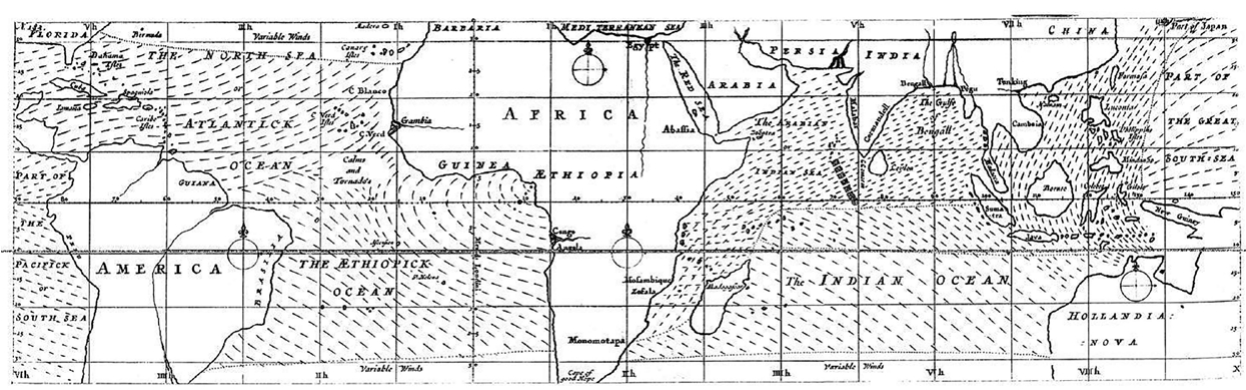

Figura 1. Mapa de vientos del ámbito intertropical. Fuente: Halley, E. (1686) Philosophical Transactions n. $^{\circ} 183$.

constantes en el ámbito intertropical es el calor originado por la radiación solar en su movimiento diario y estacional. Ese calor cuasi-constante es el causante de un proceso de rarefacción del aire en estas latitudes (un aire «sobre treinta veces más ligero» en las proximidades del Ecuador) que favorecería el movimiento de ese aire desde las áreas situadas en las líneas de Trópico (Cáncer y Capricornio) hacia la línea equinoccial. Y ello, según Halley, siguiendo las leyes de la Estática según las cuales el aire se mueve siempre desde las áreas con menor «enrarecimiento» (aire más pesado) a aquellas más enrarecidas; esto es, el aire se mueve de las zonas menos cálidas del ámbito intertropical a las zonas más cálidas.

La curvatura de estos vientos alisios hacia el SW (hemisferio norte) y hacia el NW (hemisferio sur) se debería al propio movimiento diario del Sol (Este a Oeste) y la diferente recepción de calor en los mares del ámbito intertropical que ello supone a lo largo del día. Por así decir, el viento se iría «moviendo» hacia el W siguiendo al Sol en su movimiento diario. Para justificar el carácter «constante» de estos vientos alisios, Halley señala que «se forma un viento general del este, que se imprime a todo el aire de un vasto océano, con las partes impeliéndose una a otra, para mantener el movimiento hasta el próximo regreso del sol, recuperándose entonces tanto movimiento como se había perdido, y perpetuando de ese modo el viento del este». Se transmite, indirectamente, la idea de que los vientos alisios perderían fuerza durante la noche, cuando el Sol desaparece, que no es real.

Esta misma causa primera (calor) explicaría el movimiento de los monzones en el sector septentrional del océano Índico. La diferencia aquí es la estacionalidad del calor en una zona continental que origina un flujo del SW en verano dirigido hacia el Trópico, que se torna del NE en invierno, debido no sólo al desplazamiento anual de la fuente de calor (Sol) sino al enfriamiento que se registra sobre el espacio continental en esos meses fríos del año. Halley señala que existiría una «dificultad» para explicar esta alternancia estacional de vientos 
en el océano Indico Sur puesto que aquí no se produciría, debido a su carácter marítimo, y el monzón soplaría todo el año del SE.

Por último, Halley explica las alteraciones que estos flujos de viento constantes experimentan sobre superficies continentales dentro del ámbito intertropical. Dos causas principales, según Halley, origina esta modificación en el sentido de flujo: la naturaleza del suelo y la posición de las altas montañas. Estos dos factores alteran el enrarecimiento del aire allí donde afectan y llegan a causar tanto ascensos del aire que origina lluvias («raines» en el texto de Halley), como formación de calmas sobre el océano en la misma línea ecuatorial, o por otro lado flujos de viento del W en el Golfo de Guinea. Halley señala que los flujos del Este (alisios) o del W (Golfo de Guinea) establecen un sistema en equilibrio. Además el peso del aire en estas zonas que, según Halley, se ve disminuido por el soplo de estos vientos contrarios, impide que el aire mantenga todo el vapor de agua que recibe y lo deja caer en las copiosas precipitaciones que allí se generan. Halley esboza, de este modo, una explicación -incompleta- de las precipitaciones abundantes del área ecuatorial.

Su explicación sobre la causa principal de la circulación de vientos en el ámbito intertropical es una aproximación de enorme interés por el importante papel que Halley otorga al Sol como fuente de calor y motor de los movimientos atmosféricos. No obstante, adolece de un error básico al despreciar la incidencia de la rotación terrestre y de las diferencias de velocidad angular del viento en las diferentes latitudes terrestres como agente principal de encurvación de flujos aéreos y de establecimiento, en suma, de la dirección de los vientos (vid. Figura 2).

En su ensayo no llega a proponer un modelo de circulación atmosférica general válido para todo el globo. Se ha señalado, erróneamente, que Halley defiende la existencia de una célula única de circulación atmosférica entre latitudes ecuatoriales y polares: la denominada «chimenea ecuatorial» con vientos alisios enfrentados en la línea equinoccial, ascendiendo en esas latitudes ecuatoriales y desplazándose en altitud hacia los Polos para descender allí por efecto de la mayor densidad del aire enfriado a lo largo de su desplazamiento hacia latitudes polares. Pero en ningún momento de su ensayo se llega a señalar este extremo, puesto que como reza el propio título de su trabajo, Halley se limitó a dar explicación al mecanismo de soplo de los alisios y los monzones en latitudes tropicales, entre $30^{\circ}$ norte y sur. De manera que la idea de un modelo de circulación unicelular, basado en la idea de una «chimenea» originada por el calor ecuatorial nunca existió en la propuesta de Halley, que únicamente refiere su propuesta al ámbito intertropical: «Por lo tanto, el aire al norte y al sur, más denso que en el centro, ha de tender de ambos lados hacia el ecuador: este movimiento del viento, combinado con el anterior, del este, dilucida todos los fenómenos de los vientos alisios, que indudablemente soplarían durante todo el 

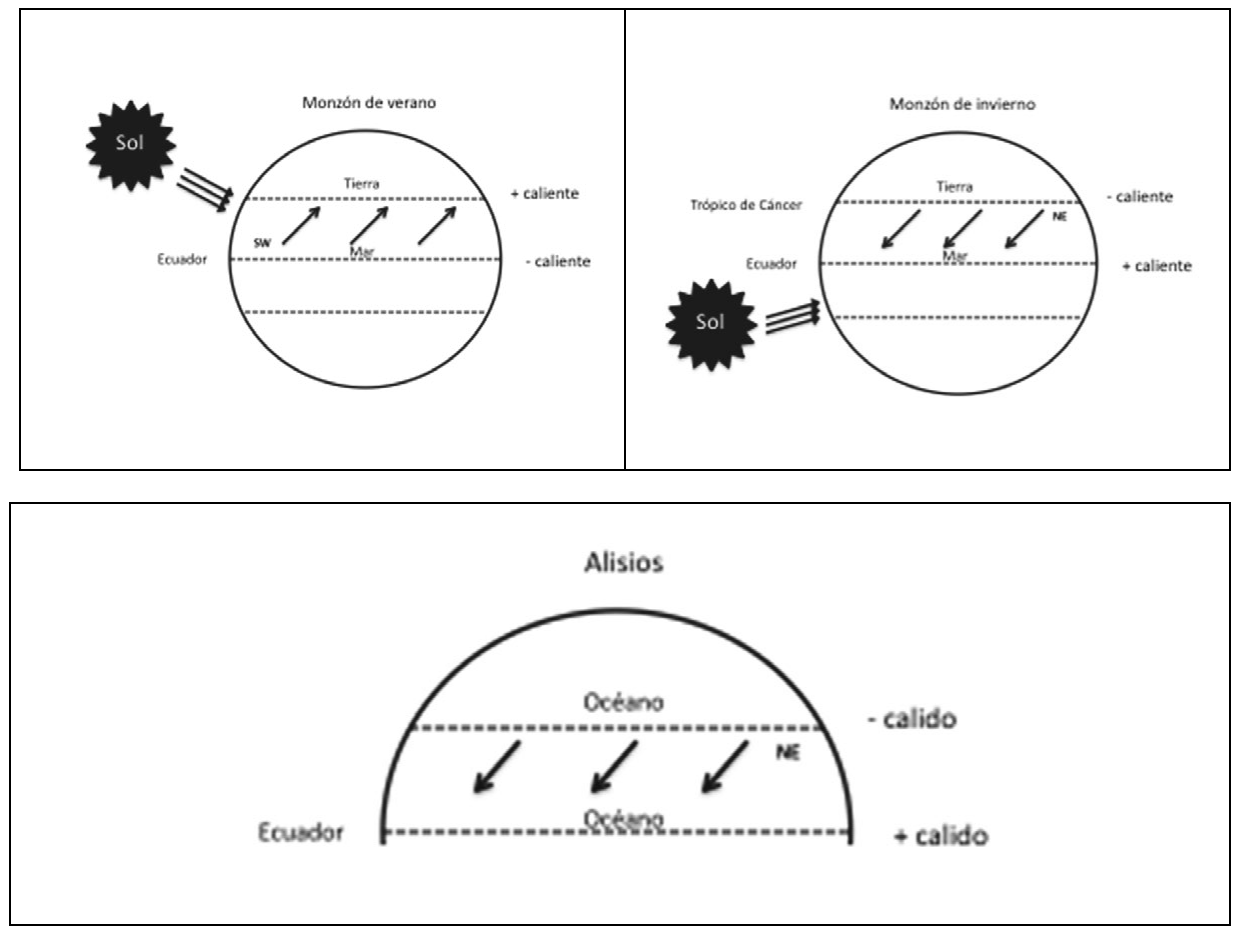

Figura 2. Explicación del mecanismo de circulación de los monzones y de los vientos alisios según E. Halley (1686).

año, si toda la superficie del globo constara de mar, como sabemos que lo hacen en los océanos Atlántico y Etiópico» ${ }^{4}$.

La explicación de la circulación atmosférica general encontrará un impulso importante unas décadas después, ya en el siglo XVIII, cuando George Hadley reflexione, asimismo, sobre el funcionamiento de los vientos alisios e incorpore la rotación terrestre como causa principal de la dirección de los mismos (Olcina Cantos, 2014).

Es de notar también que en los siglos XVII y XVIII se producen algunas aportaciones en el conocimiento de fenómenos meteorológicos extremos como los ciclones tropicales. De ellos se ocupa Varenio en el capítulo XXI de su Geografía general, y, a comienzos del siglo xVIII, William Dampier que describe un tifón en el Mar de la China.

En suma, el siglo XVII es un momento importante dentro de la evolución de las disciplinas meteorológica y climática, en el que se produce una transformación fundamental con la apuesta por la verificación científica, merced a nuevos

4. Vid. Halley, op cit. p. 166. 
planteamientos filosóficos y a la invención de todo un conjunto de instrumentos necesarios para la observación meteorológica.

\section{La CONTRIbUCión de Bernhard VARENIO a La Disciplina Climática}

Puede afirmarse que la geografía experimenta un avance importante en su camino hacia la consideración como disciplina científica con la publicación de la Geografía General de Bernand Varenio. Sus trabajos de temática geográfica y, especialmente, su Geografía General inicia un proceso de consolidación académico-científica de la geografía que se había iniciado con las aportaciones no siempre valoradas de algunos cronistas de Indias y entre ellos especialmente el padre José de Acosta y su Historia Natural y Moral de las Indias, seguirá con la Geografía Física de Kant en el siglo XVIII y culminará con las obras de Humboldt y Ritter ya en el XIX. Curiosamente, ninguno de ellos geógrafo de formación, pero que se aproximan a la temática geográfica por propia querencia o por circunstancias vitales planteando reflexiones, nuevas formas de interpretar hechos geográficos y nuevos métodos de estudios que permitirán la progresiva consolidación científica y académica de la geografía.

Las biografías suelen referirse a Varenio como un geógrafo alemán que vivió en la primera mitad del siglo XvII y tuvo una muerte prematura que le impidió terminar su ambicioso proyecto de elaborar una gran obra para el completo conocimiento geográfico de Tierra. En realidad, Varenio fue un médico que estudio en Hamburgo y Königsberg y, huyendo de la Guerra de los Treinta Años, emigró a Holanda donde se doctoró en Medicina en la Universidad de Ámsterdam con un trabajo titulado Disputatio de Febri in Genere (1648). No hay constancia de que Varenio, en su juventud, recibiera cursos específicos sobre geografía. No obstante, durante sus años de formación universitaria Varenio se aproxima a las ciencias de la tierra y del espacio que marcarán una impronta decisiva para el desarrollo de su obra geográfica posterior. Y ello lo completará con un conocimiento preciso de matemáticas y filosofía. Varenio es lo que, desde el Renacimiento, se denominará una persona de formación humanística. El paso de Varenio por Leiden y su posterior estancia en Ámsterdam serán determinantes para su proyecto geográfico.

Estamos en unos años - primera mitad del s. XVII- de fuerte actividad viajera y comercial en los Países Bajos, cuyas principales ciudades, y especialmente las portuarias, se convierten en un constante ir y venir de expediciones y viajes a regiones de Asia y del Nuevo Mundo. Es un ambiente muy favorable para la llegada y transmisión de informaciones y noticias sobre estos territorios lo que favorecerá el desarrollo de la cartografía y de las descripciones geográficas derivadas de dichas expediciones. Es lo que A. Melón denominó «período holandés» en la evolución de la disciplina geográfica (Capel, 1974). El propio 
Varenio, en la «Epistola» que precede a su Geografía General destacará la importancia de la ciudad de Ámsterdam para el desarrollo de su obra geográfica puesto que encontró una oportunidad favorable para escribir sobre temas que no habría podido desarrollar en otro lugar ${ }^{5}$. El propio Varenio señala que «no hay ciudad que más necesite del conocimiento de la Geografía que esta vuestra (Amsterdam), ni ninguna que más la utilice por sus admirables navegaciones a todos los rincones de la Tierra ${ }^{6}$.

La obra geográfica de Varenio se produce en breve tiempo; o mejor, se publica en apenas dos años (1649 y 1650), los dos últimos años de su vida. Lo que indica que ambos trabajos tuvieron una elaboración previa hasta que la prestigiosa editorial de Louis Elzevier ${ }^{7}$, establecida en Ámsterdam, publicará, en los años mencionados, la Descripción del Reino de Japón y la Geografía General (Vermij, 2007). Aunque no hay referencias concretas al respecto, estos dos trabajos de Varenio debieron elaborarse una vez establecido en Holanda en 1645.

La primera obra de temática geográfica de Varenio fue la Descripción del Reino de Japón, editada por L. Elzevier en Ámsterdam en 1649. Es un tratado muy completo sobre cuestiones geográficas, históricas, políticas, sociales, económicas y religiosas de los territorios del Extremo Oriente (Japón, Siam y regiones próximas). La obra tuvo gran repercusión en Holanda para el conocimiento de ese extremo del mundo y, como señala Capel (1980), debió ser durante mucho tiempo una de las pocas fuentes de información de los europeos sobre Japón. Se ha señalado si esta obra no era sino una muestra de la "Geografía Especial» que Varenio no llegó a desarrollar por su prematura muerte, tras la elaboración de su Geografía General. De hecho, Varenio justificó los contenidos de la Descripción del Reino de Japón en la dedicatoria de esta obra dirigida a los cónsules y senadores de la ciudad de Hamburgo indicando que «cuando los matemáticos se ocupan de la Geografía explicando la situación y los límites de las regiones, acostumbran a añadir muchas cosas acerca de las costumbres y del gobierno de los pueblos» (Descriptio Regni Japoniae, 1649, Disertatio de Rebuspublicis in genere).

Pero la gran obra de temática geográfica de Varenio fue la Geografia General escrita en latín y publicada por Louis Elzevier, como se ha señalado, en

5. Vid. Introducción de Horacio Capel a la edición de la Geografía General de Varenio, editada en Barcelona (1974 y 1980), página 26. Esta edición traduce el índice de la obra, la epístola de dedicatoria y el capítulo I donde se describe la concepción de la Geografía de Bernard Varenio.

6. Vid. Geografía General de Bernhard Varenio, edición de Horacio Capel (1980), p. 93.

7. La editora de Louis Elzevier fue una pieza fundamental para la difusión de los avances científicos y filosóficos del siglo xviI en Holanda. Esta saga familiar, con impresores en Leiden y Amsterdam editó los trabajos de Descartes, Pascal, Bacon, Hugo Grotius, Comenius, Milton y Thomas Hobbes (vid. Schuchard, 2007 a). 
1650 (Geographia Generalis, in qua affectiones generales telluris explicantur). La Geografía General de Varenio supondrá un avance clave en la evolución de la disciplina geográfica en la Edad Moderna que culminará, un siglo después con los apuntes de Geografia Física de Kant. Es un paso importante, como se ha señalado, hacia la consolidación de la geografía como ciencia, con una definición de los contenidos que le deben ser propios y unos incipientes métodos de trabajo. Recordemos que hasta la «revolución científica» la geografía vivía básicamente de las obras e ideas de la tradición clásica de Aristóteles y Plinio el Viejo que sólo había comenzado a ponerse en entredicho en algunas «Crónicas de Indias», al calor de la comprobación in situ de las ideas contenidas en aquéllas. La publicación de la obra de Varenio representará la ubicación definitiva de la Geografía en el universo de las ciencias, su consolidación como disciplina académica que se impartirá en el mundo universitario de su época y de las posteriores y la propuesta de una organización de los contenidos que debe tratar la geografía para considerarse como ciencia.

Se ha destacado que Varenio habría sido el primer autor en establecer una división de la geografía en dos partes: una general y otra regional. En realidad la división es más detallada: Geografía General (parte absoluta, parte relativa y parte comparativa) y Geografía Especial; y como señala acertadamente Capel (1980) tampoco Varenio fue el primer autor que estableció la distinción entre las dos partes de la geografía. Dicha distinción ya se encuentra tanto en el trabajo Systema Geographicum (1611) de Bartholomäus Keckermann (1573-1609), como en el de Paullus Merula (1558-1607), Cosmografiae libri tres... (1605). Pero a pesar de todo, el gran mérito de Varenius reside en haber introducido, de manera sistemática, tal distinción y principalmente, haber situado a la geografía como una ciencia moderna, basándola en los supuestos de la física moderna. Otro mérito importante de la obra geográfica de Varenio, en opinión de De Jesús y Schubring (2008) reside en el hecho de haber promovido la secularización de la propia disciplina; separó a la geografía de los fines teológicos y adoptó exclusivamente las matemáticas y los métodos empíricos de la ciencia natural. Esta secularización tuvo lugar como consecuencia de la Reforma, en particular, a causa de la escisión entre luteranos y calvinistas que provocó la ruptura de la geografía y la teología, tradicionalmente ligadas.

Varenio recoge influencias de los principales pensadores de su época que habían marcado la ruptura con el aristotelismo y ello se reflejará en diferentes partes de su Geografía General. Copérnico, Kepler, Francis Bacon y Descartes. Los dos primeros con la nueva concepción heliocéntrica del Universo de la que Varenio se hará eco en su obra. Varenio recibiría también la influencia de la filosofía de Bacon a través del pensamiento de Descartes. Esta influencia de Bacon y Descartes en la obra de Varenio se plasma en la apuesta por un método deductivo-inductivo de obtención del conocimiento, que supondrá la sistemática 
del mismo y la clasificación de las diferentes partes que Varenio distinguirá en la disciplina geográfica.

Como sabemos, en su concepción de una disciplina geográfica dividida en dos grandes partes (general y especial o regional), Varenio pudo desarrollar sólo la primera de ellas debido a su prematura muerte. La Geografía General se organiza en 3 libros (Parte Absoluta -la Tierra en si misma-, Parte Relativa -la Tierra en relación con el resto de Universo- y Parte Comparativa -comparación entre lugares de la Tierra para el calculo de distancias y orientación del rumbo de las naves-). En interesante resaltar la idea de «Geografía» de Varenio que expresa, de forma nítida, en las primeras páginas (Parte Absoluta, Cap. I) de su obra: «Geografía se llama la ciencia matemática mixta que explica las propiedades de la Tierra y de sus partes relativas a la cantidad, esto es, la figura, situación, dimensiones, movimientos, fenómenos celestes y otras propiedades similares». Esta concepción de la disciplina geográfica como ciencia matemática mixta ganará el favor de la Ciencia de su época (Newton, Halley, Jurin) que se interesará por la obra de Varenio y situará a la Geografía como una de las disciplinas importantes para el conocimiento humano.

Varenio dedica tres capítulos de la «Parte Absoluta» de su Geografía General a la cuestión atmosférica (caps. XIX, XX y XXI), aunque en otros capítulos de su obra hay referencias, asimismo, a aspectos climáticos. Para Varenio las cuestiones atmosféricas entran dentro de lo que él denomina «propiedades celestes» de los hechos geográficos que, junto a las propiedades terrestres y las humanas, deben ser la base para la descripción de las regiones de la Tierra (Geografía Especial). Las «propiedades celestes» serían aquéllas, según Varenio, que dependen del movimiento aparente del Sol y de los astros: 1) la altura del polo, la distancia de un lugar desde el Ecuador y desde el polo; 2) la inclinación del movimiento diurno de las estrellas sobre el horizonte en dicho lugar; 3) la duración del día más largo y del más corto; 4) el clima (klimata) y la zona; 5) el calor, el frío, y las tempestades del año, así como la lluvia, la nieve, los vientos y otros meteoros; 6) la salida de las estrellas; 7) las estrellas que pasan por el vértice del lugar; 8) la duración y rapidez de los movimientos, según la hipótesis copernicana. Y entre ellas, las propiedades 4 y 5 se relacionan directamente con las cuestiones climáticas.

De manera que, aunque Varenio no finalizó la «Geografía Especial o regional» en su proyecto, dejó establecido el esquema para el tratamiento de las regiones de la superficie terrestre que integraban junto a estas ocho propiedades, otras veinte de carácter «terrestre» y «humano», como se ha señalado. El fin último de esta detallada descripción para cada región del mundo era evitar que los lectores «entraran en somnolencia con la mera enumeración y descripción de las regiones sin noticia alguna de las costumbres de los pueblos que lo habitan» (Parte Absoluta, cap. I). 
Son cuatro los temas principales de contenido atmosférico y climático que aborda Varenio a lo largo de los tres capítulos de la Geografía General señalados y de las más de 82 proposiciones que los componen ${ }^{8}$.

- Composición de la atmósfera, causa del clima terrestre y características del aire

- Viento: tipos, causas y características

- Fenómenos ópticos y otros elementos climáticos

- Zonas y klimatas

Debe señalarse que, junto al mérito de presentar de forma organizada y sistemática las cuestiones atmosféricas, y de proponer nuevas ideas sobre la interpretación de algunos fenómenos meteorológicos, es cierto que Varenio mantiene aún ideas clásicas (Aristóteles) en la explicación de varios mecanismos de la atmósfera. Se puede afirmar que el mérito de Varenio consiste en recopilar y presentar los conocimientos clásicos y modernos sobre tiempo y clima de su época, a modo de breviario de cuestiones atmosféricas conocidas entonces, sin obviar opiniones y toma de postura personal. Esta organización de contenidos tendrá eco en autores posteriores, especialmente en Kant (vid. infra) que mejorará las ideas sobre aspectos atmosféricos de la Geografía General de Varenio al calor de los avances en los conocimientos atmosféricos producidos entre mediados del siglo XVII y mediados del XVIII y de sus propias ideas sobre el tema (Olcina Cantos, 2014).

\section{Composición de la atmósfera, causa última del clima terrestre y caracteristicas del aire sobre la superficie terrestre}

Varenio señala que la causa principal del clima terrestre, de sus elementos atmosféricos y de sus fenómenos meteorológicos que se dan en cada región del planeta es doble: El calor que llega desde los astros (Sol y Luna) y el calor interior de la Tierra. Estos dos mecanismos producen unas exhalaciones (vapores y humos) que son causa de otros fenómenos (nubes, nieblas, lluvias, vientos). Para Varenio la atmósfera es todo el espacio sobre la tierra donde hay vapores $\mathrm{y}$, con honestidad, reconoce que no se sabe si además de vapores, la atmósfera terrestre está compuesta por otros elementos. Resulta curioso el hecho de que Varenio defienda la importancia del «calor» lunar, aspecto desestimado en la actualidad, al no constituir la Luna una fuente de calor primaria. En esto Varenio sigue las ideas de Descartes que en sus Principia (1644, Parte 4, Proposición 49)

8. Para la elaboración del presente trabajo se ha consultado la edición de la Geografía General de Varenio editada, en inglés, en 1734 por Dudgdale y Shaw, que incluye las aportaciones introducidas por Isaac Newton y Jurin. (vid. infra, apartado 3). 
había hecho mención a la importancia de la Luna como motor de los vientos. Varenio justifica la existencia del calor lunar señalando que por la noche, con la luna en el horizonte, se observan «vapores exhalando del mar»; afirmación que con el tiempo se demostrará errónea porque dichos vapores se producen por condensación del vapor de agua sobre la superficie, más fría, del mar.

Según señala Varenio estas exhalaciones que forman la atmósfera terrestre tienen diferente composición (húmeda, salina, terrosa, sulfurosa y espirituosa) y se producen con mayor frecuencia en unos lugares de la superficie terrestre que en otros, en función de la diferente altura del Sol sobre el horizonte, la diferente fase de la Luna y su elevación sobre el horizonte, la influencia de otros astros y la diferencia entre las superficies continentales y marinas de la Tierra. En su conjunto, Varenio afirma que el aire que forma la atmósfera terrestre no es ligero sino pesado (cap. XIX, prop. 6) y que las partes altas son «más sutiles» que las inferiores. Varenio mantiene la división aristotélica de la atmósfera en 3 capas: una superior, muy ligera; una intermedia, densa y pesada; y una inferior, menos densa que la intermedia. La explicación de que la capa inferior sea menos densa que la intermedia radica en el hecho de que el aire denso y pesado inferior asciende, por efecto del calor, hacia la capa intermedia y es allí donde se concentra para formar las nubes. Sólo cuando se producen precipitaciones la capa intermedia se limpia y es entonces cuando la capa inferior resulta más densa y pesada. En la capa intermedia es donde se producen los principales fenómenos meteorológicos (nieve, granizo, lluvia) y es más fría que la superior y la inferior, debido a que no recibe directamente la radiación solar como la superior ni las exhalaciones terrestres que caldean el aire próximo al suelo (cap. XIX, prop. 18).

Varenio defiende la idea de que los movimientos principales de la atmósfera se dirigen principalmente hacia la superficie terrestre y que los ascensos de aire son siempre movimientos violentos contrarios a la corriente principal de descenso. En general, el aire caliente requiere, como señala acertadamente Varenio, mayor espacio que el aire frío que se concentra en una menor proporción de terreno ${ }^{9}$. Concluye Varenio que el espesor del aire de la atmósfera terrestre no es constante: es mucho mayor a mediodía por efecto de la radiación solar y mucho menor por la noche por la ausencia de ese calor (cap XIX, prop. 8). Esto da paso a la inclusión en este capítulo XIX de un apartado con la explicación del proceso para la fabricación de un termómetro y de un termoscopio con agua coloreada como elemento de dilatación.

9. En la edición de 1734 manejada en este estudio, y elaborada a partir de la elaborada por Jurin (1712) con textos de Newton y del propio Jurin, estos capítulos se completan con una serie de notas con referencias a los trabajos de Torricelli y Boile sobre el peso del aire y su composición gaseosa. 
Varenio dedica, a continuación, una serie de proposiciones (11 a 14) a responder sobre diferentes aspectos relacionados con la causa del enrarecimiento del aire, esto es, el calor; con el mayor peso del aire en la zona fría, debido a la menor radiación solar y a la existencia de una mayor nubosidad de modo regular; con el hecho de que en lo más riguroso del invierno el aire sea más ligero y tranquilo y ello debido a dos factores: el frío riguroso genera vapores más densos que descienden hacia el suelo, y el suelo frío cierra los poros por donde pueden producirse exhalaciones que enturbien el aire. El resultado, señala Varenio, es que el aire es más ligero y tranquilo en esos momentos del año de mayor frío; y, por último, con la mayor densidad del aire en la línea del horizonte, lo que relaciona con la gran distancia respecto al observador y el menor ángulo de observación y a la existencia cierta, según Varenio, de mayor nubosidad en el horizonte. Este segundo aspecto resulta ciertamente cuestionable.

Varenio se pregunta, asimismo, sobre el peso y la altura del aire sobre la superficie terrestre para concluir que si bien el peso es el mismo en todos los lugares de la Tierra debido a su forma esférica y no se altera ni por la condensación ni por la rarefacción del aire, la altura del aire, por el contrario, no es la misma en toda la superficie terrestre. Y ello está en función, según Varenio, del carácter más frío o más cálido del aire existente en cada región de la Tierra y de la estación del año en la que nos encontremos (cap. XIX, props. 16 y 17). Es una cuestión de gran interés, porque supone un precedente, con base científica, sobre la diferente altitud de la tropopausa en la atmósfera terrestre que sólo se confirmará a lo largo del siglo xx.

De manera que la diferente radiación solar en las zonas terrestres es una causa fundamental del clima terrestre y se manifiesta, asimismo, en la diversa «altura» de la capa atmosférica que envuelve la Tierra y en los movimientos de rarefacción que origina el calor en el aire. Pero, además, esa distinta radiación solar en las regiones terrestre es causa, según el geógrafo alemán, de las diferencias estacionales a lo largo del año (Libro II, cap. XXVI). En esta cuestión resulta muy interesante la distinción que Varenio realiza entre estaciones del año «astronómicas», vinculadas a la presencia de unas u otras constelaciones en el cielo y estaciones, que él denomina «terrestres», que son las estaciones climáticas del año y cuyos rasgos difieren según el lugar de la tierra donde nos encontremos.

No obstante, a pesar de la importancia principal otorgada a la radiación solar para explicar la distribución de los rasgos climáticos básicos en las zonas terrestres, Varenio señala, acertadamente que existen otra serie de factores que justifican la diferencias climáticas regionales y que enumera por este orden: la proximidad del mar, el carácter de isla o no de un espacio geográfico, la existencia de relieves, el efecto de los vientos, la presencia de mayor o menor 
cobertura nubosa que explica el menor calor registrado en las proximidades de la línea equinoccial.

\section{Vientos}

El viento es, sin duda, el elemento principal de estudio en la obra de Varenio, dada su importancia para la navegación y comercio de la época y para la explicación de la propia temperie diaria, siguiendo así la tradición de relacionar viento y tiempos atmosféricos que se remonta al s. v a.C. con el tratado de Hipócrates. Frente a las numerosas páginas que Varenio dedica en su Geografía General a explicar aspectos diversos sobre el viento, otros elementos climáticos asimismo básicos en la explicación de los climas terrestres -temperaturas, lluvias- merecen un tratamiento mucho menor en su obra.

Varenio, en efecto, dedica dos capítulos (cap. XX y XXI) al viento; se aborda en ellos las causas, aspectos significativos de su soplo, se presenta una tipología de vientos y una clasificación en función de su rumbo que pretende superar a la mantenida desde época clásica (Aristóteles, Los Meteorológicos). En este último aspecto, Varenio maneja un término de origen latino «plaga» (de plaga, ae, que significa extensión, espacio, zona y que deriva del término griego $\pi \lambda \alpha \xi$, planicie, llanura, superficie), que había sido utilizado por San Isidoro en sus Etimologías y manejado, asimismo, por el padre Tosca en el libro II de su Geografía (Capel, 1980). El geógrafo alemán lo entiende como «un plano imaginario, perpendicularmente extendido desde cualquier punto de la tierra a uno de los que están en la circunferencia de un círculo, que tiene ese punto de su centro» (Cap. XX, prop. 3). En definitiva, equivale a un rumbo de la rosa de vientos que identifica el punto cardinal de donde procede el viento. Varenio señala que estos puntos sobre la brújula son infinitos, pero que son 32 los que pueden ser nombrados mediante un sistema de referencia a partir de los cuatro puntos cardinales principales. Y justifica esta nueva manera de clasificar $\mathrm{y}$ denominar los vientos en el hecho de que las denominaciones propuestas en época clásica (Aristóteles y Séneca) resultaban incómodas para los navegantes; incluso, ante la afirmación de Séneca según la cual no pueden existir más vientos que doce, Varenio señalará tajante que esta afirmación «es errónea y ridícula. Porque hay infinitos» (Cap. XX, prop. VIII).

El capítulo XXI de la Geografía General está dedicado, casi en su totalidad, a la explicación de la causa de los vientos. Este capítulo resulta, sin embargo, un poco confuso en la organización de sus contenidos, porque aunque se inicia con una propuesta de clasificación de tipos de vientos en función de la duración y de la extensión territorial de su soplo, y prosigue con la explicación de los tipos de viento principales, retoma las propuestas de clasificación con nuevas categorías de vientos en diferentes apartados. La organización temática 
sistemática de los dos capítulos anteriores no se encuentra, de modo tan evidente, en éste.

Ya en el capítulo XX Varenio había señalado que eran varias las «causas de los vientos». Siguiendo las ideas de los clásicos y apoyándose en su coetáneo Francis Bacon ${ }^{10}$, proporciona la siguiente descripción sobre el origen del viento: «La causa general y principal es el sol mismo, el cual, mediante sus rayos de fuego, enrarece y atenúa el aire, sobre todo el que se encuentra debajo de él. El aire enrarecido ocupa un mayor espacio, lo que hace que el aire empuje hacia adelante el aire contiguo; y el Sol, teniendo un curso circular del este al oeste, hace que la presión se ejerza hacia el oeste, como parece ser el caso en la mayoría de los lugares de la zona tórrida y en todos los alrededores, donde reina continuamente sobre el mar un viento del este; el aire enrarecido presiona hacia el oeste dentro de los trópicos. Existe, efectivamente, una presión por todos lados; pero el aire apenas es admitido en los otros puntos porque la presión no es tan grande como del lado de oeste, dado que el sol se mueve hacia ese lado» (Cap. XX, prop. X). Y junto al Sol, Varenio enumera seis procesos más que «ayudan» a esta causa principal:

- las exhalaciones del mar y de la tierra que contribuyen a rarificar el aire

- la rarefacción o atenuación de las nubes

- la fusión del hielo y la nieve

- el ascenso de la Luna y los astros

- la condensación y rarefacción del aire por el frío y el calor

- el descenso de las nubes que presiona el aire inferior

Varenio hará alusión en esta misma proposición X del capítulo XX de su obra a la Eolípila, máquina inventada por Herón de Alejandría en el s. I a. C., para justificar, de modo práctico, el papel primordial del calor, procedente del Sol, como causa primera del movimiento del aire.

Es de destacar la tipología de los vientos que aporta el geógrafo alemán en el capítulo XXI; nos habla de vientos constantes -aquel que sopla durante una o dos horas procedente del mismo sitio- y que tienen como causa principal el Sol o la fusión de la nieve y los inconstantes, que no cumplen dicho rasgo; de vientos generales -aquellos que soplan en diversos sitios de la superficie terrestre, pero al mismo tiempo y a lo largo casi de todo el año- y de vientos particulares; de vientos periódicos y fijos, y de vientos irregulares y ocasionales.

10. Vid. Francis Bacon Historia naturalis et experimentalis de ventis, Londini: In officina Io. Hauiland, impensis Matthaei Lownes \& Guilielmi Barret, 1622. Se trata de un trabajo de 285 páginas incluido dentro de la obra de este mismo autor «Historia naturalis ad condendam philosophiam, sive, Phaenomena vniuersi quae est Instaurationis magnae, pars tertia». 
El geógrafo alemán responde a cuestiones diversas que tienen que ver con el soplo de los vientos en función de su procedencia, destacando que los vientos del Este son más frecuentes que los del Oeste, que los vientos del Sur y del Oeste son más templados que los del norte y que los vientos del norte y del Este tienen más potencia (velocidad) e ímpetu que los del Oeste y los del Sur. Es curioso el escaso protagonismo que otorga Varenio a los vientos del oeste frente a los del este, máxime cuando su Geografía General se escribe y de edita en un ámbito de la Europa Occidental proclive a grandes vendavales del oeste.

Pero como se ha señalado, hay un interés particular entre los siglos XVI a XVIII por encontrar la causa última del soplo de los vientos alisios que permitían una navegación fluida y veloz hacia los territorios remotos (América, África y Asia) a su paso por las latitudes intertropicales. No es extraño que, entre las noticias que Varenio pudo recoger de los navegantes en la ciudad de Ámsterdam, la justificación del soplo de esos «vientos constantes» del Este que los viajeros encontraban en sus travesías oceánicas ocuparan un protagonismo principal, que luego reflejó en estos apartados dedicados al viento en su Geografía General.

No en vano, Varenio aporta su explicación del soplo constante de estos vientos del Este («General Winds»): «...el sol es la principal causa que enrarece al aire del este hacia el oeste; por consiguiente, el aire es más presionado del lado del oeste. Este movimiento no puede ser impedido, a no ser por una gran cantidad de exhalaciones o nubes en la parte oeste, lo cual no es frecuente»; y añade: «los naturalistas señalan tres causas de este viento general (puesto que los antiguos no tenían ningún conocimiento ni siquiera de la zona tórrida). Algunos piensan que el movimiento del sol del este al oeste es la causa, porque enrarece el aire por donde pasa, y que esta rarefacción sigue al sol que empuja el aire delante de sí. Otros, es decir, los que suponen que los cielos son inmóviles y que la Tierra gira, son del parecer que el viento general viene del movimiento de la Tierra del oeste al este, y que el aire gira con ella, pero no tan rápido como nosotros; y por consiguiente, dicen que vamos contra el aire, o el aire contra nosotros del este al oeste. La tercera causa, nueva, fue imaginada por Descartes...donde trata de mostrar que ese movimiento del aire es causado por la luna también, como las mareas...» Entre estas tres causas, Varenio se decanta por la primera y rechaza la segunda «porque varios copernicanos la han rechazado, y no podemos aducir ninguna razón de por qué no soplaría sino entre los trópicos, y no más allá» ${ }^{11}$.

Señala Varenio dos ámbitos mundiales donde los vientos del Este soplan todo el año: el océano entre Sudáfrica y Brasil (Atlántico sur) y el océano entre América y las Islas Orientales (Pacífico); en otros ámbitos oceánicos del planeta

11. En las ediciones de la Geografía General preparadas por James Jurin $(1712,1736)$, se incluiría, en este apartado, la referencia a la aportación realizada por Edmund Halley en su célebre artículo de 1686 sobre las causas de los vientos alisios y los monzones. (vid. supra) 
estos vientos no merecerían el calificativo de «vientos generales», por ejemplo entre Sudáfrica y las Indias orientales, debido en este caso a la aparición del fenómeno de monzón, o en el Atlántico norte en África intertropical debido a la existencia de un área de calmas en el Golfo de Guinea.

Un viento regional que había sido justificado por varios autores clásicos, merece también la atención de Varenio en su Geografia General: el viento etesio. Varenio mantiene el argumento clásico aristotélico para justificar el soplo de los vientos etesios o «dog-winds», denominados así en relación con la coincidencia de su soplo con la aparición en el horizonte de la estrella Sirio, perteneciente a la constelación Canis Maior, en el mes de julio. Aristóteles en Los Meteorológicos había aportado el siguiente origen para los vientos etesios: «Algunos se plantean como problema por qué los vientos del norte, a los que llamamos etesios, soplan continuamente después del solsticio de verano...La explicación es que el viento del norte sopla desde las regiones árticas que están repletas de agua y abundante nieve, derretida la cual por la acción del sol, soplan los etesios más bien tras el solsticio de verano que en éste». Otorga pues un protagonismo básico a la presencia de nieve como elemento generador de este viento constante y lo contrapone a la menor constancia del viento cálido del Sur porque según Aristóteles «sopla desde el trópico de Cáncer y no desde el otro polo».

La presencia de nieve como fuente o manantial generadora de vientos constantes como los etesios, es un argumento que Varenio utilizará para explicar los rasgos de algunos vientos regionales. Así, al hablar de los vientos que soplan del sur en Chile y Perú, para los que señala que son «fríos y secos porque vienen del polo Sur» (Cap. XXI, prop. VIII). E incluso, es también argumento principal para justificar la existencia de calmas en el Golfo de Guinea, donde la ausencia de vientos genera fuertes contratiempos para los navegantes que desde Europa se dirigen hacia la India hasta el tiempo de tener parados los navíos hasta un mes (Cap XXI, pro. XVI). En efecto, Varenio, que reconoce que este asunto «no es una dificultad pequeña» para dar una respuesta acertada, indica que «no hay montañas nevadas en África, entre Guinea y Barbaria ${ }^{12}$, que origine un viento constante» y ello genera la existencia de las calmas.

Varenio dedica un extenso apartado del capítulo XXI de la Geografía General a la explicación de los vientos periódicos, que engloba bajo el concepto común de «monzones» (Cap. XXI, proposición 3). Señala que algunos de estos vientos monzónicos cambian de dirección dos veces al año en diferentes partes del mundo, pero señala que no con la misma fuerza. Incluye una relación de aquellos lugares del mundo donde son importantes los vientos periódicos. Se trata de un listado amplio de áreas terrestres que registran vientos constantes

12. Denominación geográfica manejada por los europeos durante los siglos XVI y XIX para referirse a las regiones costeras del norte de África, entre Marruecos y Libia. 
en una época del año (vientos periódicos), pero que realmente no corresponden a lo que se entiende como circulación de monzón propiamente dicha, aunque Varenio emplee este concepto ${ }^{13}$. Se comprueba en este apartado la recopilación de información realizada por el geógrafo alemán, en su estancia en la ciudad de Ámsterdam, a los navegantes que hacían las rutas de comunicación fluvial entre Europa y Asia, África y América:

- El Atlántico intertropical, donde los vientos soplan del norte de octubre a enero («la mejor época para navegar de Europa a la India»)

- En Cabo Verde, donde los soplan del Sur en verano y originan «el invierno lluvioso» allí.

- En el Cabo de Buena Esperanza, donde sopla viento del Noreste en septiembre.

- El Reino de Patani (sudeste asiático) que registra vientos del Noreste en invierno y del Este en verano.

- Sumatra, donde el monzón cambia en noviembre y diciembre

- Las islas Azores, que registran un viento periódico del sur en Agosto

- La región del Congo, con vientos del Norte y Noroeste de marzo a septiembre, y del Sur y Sureste de septiembre a Marzo.

Sobre las causas de estos vientos periódicos, Varenio señala que son diversas en cada área del mundo, pero apunta tres. Dos de ellas principales: la fusión de la nieve de las montañas y la disolución de las nubes en áreas de hemisferio norte y sur. Ambas, según Varenio, están originadas por la propia radiación solar, que incide más en un hemisferio que en otro en cada mitad del año. Cuando el Sol está en el hemisferio norte, soplarían desde el norte y viceversa. Además, indica una tercera causa de los vientos periódicos: el mismo movimiento de la Luna y la fase lunar en que se encuentre en cada momento del año que «pueden causar un cambio en esta cuestión» (Cap. XXI, prop. 3).

Junto a las áreas mundiales donde soplan esos vientos periódicos, Varenio afirma con rotundidad que la región del mundo donde «los monzones son más famosos» es el Océano Îndico, entre África y la India, puesto que aquí el cambio en la dirección de los vientos tiene lugar cada seis meses. Se describen, a continuación, con detalle los lugares de Asia meridional y oriental (entre las islas del Índico hasta Japón) donde se observa este mecanismo de vientos periódicos, indicando el momento exacto del año en el que se produce el cambio en el rumbo de los vientos. En este espacio del mundo los vientos soplan, según indica

13. Tanto en este detallado apartado sobre los vientos periódicos como en el dedicado a los vientos constantes del Este en el ámbito intertropical se puede apreciar la importante labor de recopilación de información realizada por Varenio a los navegantes que hacían las rutas de comunicación fluvial entre Europa y Asia, África y América. 
Varenio, del oeste en una parte del año (verano) y del este en la otra (invierno) ${ }^{14}$. Varenio afirma que los vientos periódicos más constantes se encuentran sobre el océano, pero no ofrece una causa para la explicación del monzón en el sur de Asia porque es consciente de las diferencias existentes en este extenso espacio terrestre lo que impide una única causa para justificar su soplo y su rumbo. Y asimismo, señala la necesidad de disponer de un mayor número de observaciones de varios años para poder sacar conclusiones sobre su funcionamiento, «así como del mejor conocimiento en la estación invernal, de las lluvias, las nieves y de las montañas es esos lugares desde las que esos vientos comienzan a soplar». De manera, que estos vientos del monzón asiático quedarían justificados por la causa general ofrecida por Varenio para comprender los vientos periódicos, que se ha señalado con anterioridad (vid. supra).

Es curiosa la explicación de la causa de los tifones que ofrece Varenio. La proposición $n .^{\circ} 12$ del capítulo XXI está dedicada a este fenómeno meteorológico, definido como «un viento fuerte y veloz que sopla desde todos los puntos circulando por todas partes y por lo general viene de arriba» y que es frecuente en el «Mar Oriental, entre Malaca y Japón» especialmente en verano. Para Varenio, los tifones se forman cuando «el viento que circula hacia un lugar se obstruye, y vuelve sobre sí mismo; y en este retorno, como se observa en el agua, se convierte en un torbellino cuando se encuentra con un obstáculo; o puede proceder de vientos furiosos que se encuentran unos contra otros sobre la superficie del mar y se lanzan contra los navíos. Si este viento sopla desde lo

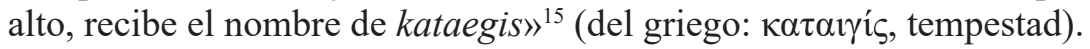

Varenio se refiere también a las «tempestades» (temporal de viento) procedentes de nubes de tormenta que soprenden a los navegantes en algunas zonas del mundo (Cap. XXI, proposición 10). Especialmente en el mar Etíope, entre Brasil y Sudáfrica, y que corresponde al fenómeno que los griegos denominaban Ecnephia (viento de fatalidad) y los portugueses «travados» (del portugués, bloqueado) ${ }^{16}$. Son, sin duda, frentes de tormenta, donde el viento en este caso se acompaña de fenómenos eléctricos pero no tanto de lluvia. Varenio señala que en la ruta entre Europa y Asia, este fenómeno es temido por los navegantes y en especial cuando se desarrollan en el Cabo de Buena Esperanza que el geógrafo alemán califica como lugar «desastroso por tales tempestades procedentes de las nubes». Varenio siguiendo a los clásicos distingue entre estas «tempestades» de viento (Ecnephia) y las tempestades que originan fuertes lluvias y

14. La circulación genuina del en el sur de Asia sopla del noreste (NE) en invierno y del suroeste (SW) en verano.

15. Este término no hizo fortuna en las ciencias atmosféricas, pero se emplea en la actualidad en biología molecular para hacer alusión a áreas de hipermutación regional.

16. Esta expresion, que no tuvo fortuna en el vocabulario meteorológico, será recogida, asimismo, por Kant en su tratado de Geografía Física, relacionándola con el fenómeno del ciclón tropical. 
mangas de agua (Exhydrias, del gr. «viento lluvioso»), donde el protagonismo correspondería, justamente, a la precipitación.

Es curioso observar que Varenio se refiere a tifones (vid. supra) y huracanes como fenómenos atmosféricos distintos. En el caso de los huracanes, Varenio los incluyen dentro de las denominadas «tempestades» de viento procedentes de las nubes e indica que son vientos repentinos y violentos, con o sin aparato eléctrico, y que revisten carácter periódico en diversas partes del mundo. Es para Varenio un fenómeno meteorológico con origen en una nube que siendo pequeña al principio pero van creciendo sobre el mar hasta desarrollar temporales violentos.

Como balance de los conocimientos sobre vientos comentados por Varenio en su obra y en relación con su interés de sistematización, el geógrafo alemán ofrece una clasificación-síntesis de los vientos planetarios en función del lugar y tiempo de soplo (vid. Tabla 1).

Tabla 1. Clasificación de vientos de Varenio en su Geografía General (1650)

\begin{tabular}{|l|l|}
\hline CLASE DE VIENTO & RASGOS BÁSICOS \\
\hline Comunes (Vientos Generales) & $\begin{array}{l}\text { Soplan en todos los lugares y en todas las épocas del } \\
\text { año }\end{array}$ \\
\hline Particulares & $\begin{array}{l}\text { Soplan en todas las épocas del año pero sólo en ciertos } \\
\text { lugares de la Tierra }\end{array}$ \\
\hline Periódicos o cotidianos (monzones) & $\begin{array}{l}\text { Soplan en varios lugares pero no en la misma época } \\
\text { del año }\end{array}$ \\
\hline Ocasionales & $\begin{array}{l}\text { Aquellos que no soplan en todas las épocas del año ni } \\
\text { en muchos ligares }\end{array}$ \\
\hline
\end{tabular}

Elaboración propia

Resulta necesario observar, como balance de las ideas y reflexiones sobre los vientos que Varenio recoge en la Geografía General, que junto a la extensión de los apartados dedicados a explicar los vientos «generales» del Este, los monzones, las calmas, las tempestades marinas en mares tropicales o los tifones, no hay apenas mención a fenómenos de lo que se denominan en la actualidad «latitudes medias». Hay, sin duda, dos razones para ello: la causa principal para el movimiento del aire atmosférico es para Varenio el calor del Sol y el área del mundo donde este calor se manifiesta con intensidad y permite justificar el origen de los fenómenos atmosféricos que allí se dan es el ámbito intertropical; y en segundo lugar, el trabajo de Varenio tiene una clara finalidad «aplicada» en este aspecto: la justificación de fenómenos meteorológicos que pueden tener interés para la navegación marítima entre Europa y las regiones lejanas de África, Asia y América; y esos trayectos el paso por los océanos y mares del 
ámbito intertropical era el acontecimiento náutico más destacado en la época de la navegación a vela.

\section{Fenómenos ópticos y otros elementos climáticos}

Los fenómenos ópticos ocupan también una extensión destacada en la obra de Varenio. Sin duda, por la influencia de los trabajos de Descartes al que cita en diversas partes del capítulo XIX de su Geografía General. De entrada, el geógrafo alemán señala que las partículas de aire reflejan los rayos de Sol como un espejo, aunque no todas, puesto que algunas, transmiten el calor y reflejan sólo una pequeña porción (cap. XIX, prop. 5); y ello en relación con la propia composición de las partículas («como átomos», en expresión del propio Varenio) que compone el aire y que en unos casos tienen poros y en otros no, siendo esto determinante en la difusión de los rayos o en su reflexión. Varenio dedica una veintena de proposiciones del capítulo XIX a dar explicación a fenómenos ópticos en la atmósfera terrestre que inicia con una definición de la refracción que sería el fenómeno según el cual «los rayos del Sol, la Luna y las estrellas no llegan directamente desde los cielos, a nuestros ojos, sino que se aleja un poco de la línea recta tan pronto como entra en el aire». Este hecho origina que el Sol y otros astros aparezcan antes en el horizonte en su movimiento, mientras estén por debajo de un ángulo de $20 .^{\circ}$ Varenio señala que el fenómeno de la refracción es más intenso cuando mayor es la densidad del aire en la atmósfera y por ello en atmósferas densas el Sol y los astros aparecen más rápidamente en el horizonte. Por tanto, afirma Varenio que una estrella puede experimentar diferente refracción en un mismo lugar, dependiendo de la densidad del aire en cada ocasión. Estas apreciaciones sobre la relación entre densidad del aire y altura de la capa de aire donde se produce el fenómeno de la refracción es manejada por Varenio para calcular la altitud de la columna atmosférica en un lugar. El geógrafo alemán afirma que la refracción de una estrella -se entiende de la radiación procedente de un astro- «es igual a la diferencia entre la altitud observada y la altitud verdadera, que se conoce por cálculo algebraico. Varenio explica esta cuestión con una serie de ejemplos prácticos que se desarrollan en las proposiciones 30 a 34 del capítulo XIX. Por su parte, las proposiciones 35 a 39 están consagradas a la explicación del fenómeno óptico de la reflexión de los rayos, porque, como hace constar Varenio, los rayos del Sol y de la Luna no sólo experimentan refracción cuando entran en la atmósfera, sino que son también reflejados por las partículas existentes en el aire contra las que chocan «como si procedieran de un espejo rugoso debido a la situación irregular de dichas partículas en el aire» (Cap. XIX, proposición 35). Varenio relaciona el crepúsculo (orto y ocaso) con la reflexión de los rayos del Sol que ocurre por la mañana y al anochecer y señala que se produce cuando los rayos solares tienen 
una inclinación alrededor de $18 .^{\circ}$ sobre el horizonte. Se plantea Varenio una cuestión interesante y es el hecho de que la altitud del aire no se puede deducir de la magnitud del crepúsculo, puesto que no se puede saber si este fenómeno procede de una única reflexión o de una doble reflexión; son necesarias, indica, «otras observaciones para calcular dicha altitud».

Frente a la extensión que dedica Varenio en la Geografía General a la explicación de la composición de la atmósfera, de los vientos o de los procesos ópticos en el aire señalados, otros meteoros apenas merecen tratamiento en su obra. En el capítulo XXVI da la clave de la causa última de los meteoros (tempestades, lluvias) y señala que se deben a la diferente radiación solar en las zonas terrestres. Y esto es también la causa, afirma el geógrafo alemán, de las estaciones del año. No obstante, y a pesar de incluirlo en el capítulo dedicado a los vientos (Cap. XXI, proposición 10), Varenio detalla las causas de las tormentas señalando dos posibles orígenes: bien proceden de las nubes que al descender empujan el aire que hay debajo de ellas y originan una tempestad; o bien proceden de exhalaciones sulfurosas que penetran en una nube y la rompen forzando a los vientos internos de la nube a salir de forma violenta. Entre estas dos causas, a Varenio le resulta más convincente la primera.

Por su parte, el reparto de los climas terrestres, junto al factor astronómico de la diversa radiación solar, se explica también, según Varenio, por la proximidad al mar, el factor de insularidad, la presencia de cadenas de relieves, el efecto de los vientos y la presencia de nubes que, por ejemplo, en la zona tórrida ejercen de parasol permitiendo la existencia de un clima húmedo y menos cálido que en latitudes subtropicales. Por último, Varenio realiza una propuesta para el tratamiento de las cuestiones climáticas en la explicación de las diferentes regiones de la superficie terrestre, que hubiera tenido que aplicar en su Geografia Especial, lamentablemente no escrita. Al final del Capítulo I de la Geografia General, Varenio señala, como se ha indicado (vid. supra), aquellos factores (elementos) que considera básicos en la descripción de las regiones y entre esos 28 aspectos principales indica que hay que explicar el «klimata y el tipo de zona» a la que pertenece esa región, así como el «calor y meteorología del año (vientos, lluvias y otros fenómenos atmosféricos)». En este sentido y aunque la Geografía General de Varenio no ofrece una descripción de las variedades climáticas existentes en la superficie terrestre, la proposición 42 del capítulo XIX es un delicioso apartado, a modo de esbozo de climatología regional, donde se detallan los caracteres que presenta el aire en diferentes partes del mundo. Así por ejemplo Varenio señala que en Egipto «raramente o prácticamente nunca llueve» y si llueve provoca «enfermedades, catarros, fiebres y asmas», de manera que «la inundación del Nilo sacia su necesidad de agua»; en el Reino del Perú «nunca llueve», mientras que en muchos lugares bajo la línea ecuatorial «lluvia la mitad del año, mientras que en la otra mitad ocurre lo contrario» (Cap. XIX, proposición 42). Resulta sorprendente, en este apartado, la afirmación que 
realiza Varenio de que la isla de Timor «está cubierta de nieblas y escarchas»; en la isla de Sumatra «el aire es insalubre a causa de la abundancia de lagunas» y lo mismo señala para México y Malaca. Afirma Varenio que la isla de St. Thomas, en el mar Caribe, tiene el aire más «groseramente insalubre», mientras que en la provincia de Chile el aire es tan «fino y sutil que la hoja de la espada envainada y sin limpiar no se oxida»; por su parte en las Azores los vientos son «tan afilados que en poco tiempo corroen láminas de hierro y azulejos en las casas, reduciéndolos a polvo». Se refiere Varenio, asimismo, a los problemas de respiración y de congelación relacionados con la presencia de altas montañas, como ocurrió «con los españoles que se desplazaban desde Nicaragua a la provincia de Perú» en América. Por su parte, en el aire en las islas del océano Índico es «tan fragante como el olor de las especias» que los navegantes lo perciben cuatro millas antes de llegar a ellas «especialmente cuando el viento sopla en contra de los navíos». Por último, Varenio afirma que el aire del mar es más «insalubre» que el aire procedente de tierra y ello «lo saben bien los navegantes que cuando se acercan a la orilla aprovechan para respirar el aire terrestre» (Cap. XIX, proposición 42). Este apartado culmina con unas ideas sobre la altitud del aire y de las nubes en zonas de montaña, a partir de un documento de 1615 elaborado por un observador, David Fraelichius, sobre los montes Cárpatos donde se indica que la distancia entre la superficie terrestre y las nubes varía en función del aire que se eleva en las zonas de montaña.

\section{Zonas y klimatas}

En relación con este aspecto de gran importancia en tratados geográficos desde época griega, Varenio dedica los capítulos XXIV, XXV y XXVI del Libro II (Parte Relativa) de la Geografía General, a la explicación de las «zonas» y de los «klimatas» en la superficie terrestre. Recordemos que estos dos sistemas de representación de la Tierra se remontan a época griega (Olcina Cantos, 1999) y suponen una forma de establecer divisiones «regionales» de la superficie terrestre a partir de dos criterios de base climática: la radiación solar y la insolación. Se distinguirán 5 zonas terrestres (una tórrida, dos templadas y dos frías) y un número de klimatas que irá aumentando conforme se amplíe el mundo conocido. Varenio defiende la existencia de las 5 zonas, con la tórrida dividida en dos por la línea equinoccial (Libro II, cap. XXIV) y aporta como novedad la descripción de los países y regiones que se incluyen en cada una de estas zonas terrestre.

Otra aportación importante de Varenio en esta cuestión es la descripción de una tabla para la elaboración de klimatas que recoge hasta 24, entre el Polo y el Ecuador, incluyendo tanto territorios conocidos y desconocidos. Esta división de klimatas será utilizada en la elaboración de planisferios desde la segunda mitad del siglo XVII hasta bien entrado el siglo XIX. La tabla de klimatas de Varenio establece que el paso de un klimata a otro supone la ganancia de $1 / 2$ hora 
de luz solar el día del solsticio de verano, entre los $0 .^{\circ}$ y los $66 .^{\circ} 31^{\prime}$ de latitud. A partir de esa latitud y los $90 .^{\circ}$, se establecen 6 klimatas más «de mes», esto es, el paso de uno a otro supone la ganancia de un mes de luz solar en el intervalo comprendido entre los equinoccios de primavera y otoño.

Varenio acepta plenamente la idea de la habitabilidad de la zona tórrida y alude en varios apartados de su obra a lo que denomina el «error de los antiguos» que afirmaban que la zona tórrida no podía ser habitada. La idea de una zona tórrida que no podía estar ocupada por el ser humano sólo podía ser concebida en el marco de una concepción científica "geocentrica», con la negación del movimiento de la propia esfera terrestre girando sobre sí misma y sin inclinación de su eje de rotación. Los cronistas de Indias comprobaron sobre el terreno que la zona tórrida era habitable. Así se recoge en los textos de Fernández de Oviedo o José de Acosta. Pero la demostración científica se fijaría en el marco de las nuevas ideas heliocéntricas de los siglos XVI y XVII, que defenderán la rotación de la Tierra sobre un eje inclinado. Es así como se puede confirmar, desde la ciencia, la habitabilidad del ámbito intertropical en la superficie terrestre. Será Copérnico en el Libro III de su obra «De revolutionibus orbium coelestium»(1543) quien fijará la idea de la inclinación del eje de rotación terrestre.

Zonas y klimatas siguen vigentes, por tanto, en el siglo XVII como criterio, de base climática, para la división cartográfica de la superficie terrestre y así se mantendrán en la centuria siguiente, a pesar de las mejoras experimentadas en las mediciones de los paralelos y meridianos terrestres.

$* * *$

Los apartados dedicados a las cuestiones atmosféricas en la Geografia General de Varenio suponen un interesante esfuerzo de sistematización de los conocimientos sobre tiempo y clima existentes en su época. Hay apreciaciones sensatas, juiciosas y racionales junto a algunas aportaciones novedosas en la explicación de fenómenos meteorológicos (viento), aunque se comprobarán, empero, incorrectas con posterioridad; hay incorporación, siguiendo los trabajos de pensadores de su época (Descartes), de nuevos temas al corpus de contenidos propios de la meteorología y climatología (fenómenos ópticos); hay una interesante propuesta de integración de las cuestiones atmosféricas como factor importante en la explicación de hechos geográficos de las distintas regiones del mundo (Capítulo I). Y junto a ello hay también cuestiones que siguen justificándose a partir del pensamiento clásico (Aristóteles), como es el mantenimiento de la idea de las exhalaciones atmosféricas y su división, la existencia de tres capas atmosféricas, la relación entre las exhalaciones y la circulación del viento o el mecanismo originador de los vientos etesios. Y, por último, hay un tratamiento muy escueto de otros meteoros. 
Por ello, no se puede otorgar el apelativo de «manual» o «breviario» de climatología a la recopilación de capítulos dedicados a los aspectos atmosféricos en la Geografia General de Varenio, como sí lo merecerá, un siglo y medio después la Geografía Fisica de Kant. No obstante, hay que reconocer que la obra de Varenio es un eslabón importante en la evolución de las disciplinas climática y meteorológica como nexo entre una tradición clásica que va perdiendo peso como autoritas en la explicación de hechos científicos y una ciencia nueva que va cuajando, a partir de ahora, sus primeras aportaciones de interés.

\section{REPERCUSIÓN POSTERIOR DE LA OBRA DE VARENIO: INMANUEL KANT Y A. VON} HuMBOLDT

La Geografía General de Varenio tuvo gran repercusión en Europa Central y conoció varias ediciones y en diversas lenguas. Tras su primera edición latina, en Ámsterdam (1650), la obra se volvería a editar en 1664 y 1671. En 1672, el propio Isaac Newton que la había calificado como «la obra de Geografía más importante de su tiempo», llevo a cabo una edición -también en latín- en Cambridge, que completo con notas y nuevos datos. De esta edición se realizaron dos reimpresiones en 1681 y 1693. Ya en la centuria siguiente, el físico británico James Jurin llevó a cabo una nueva edición en latín, ampliada con un extenso anexo (1712). Esta edición mereció reimpresión en Nápoles, tres años después, no sin controversia puesto que se modificó la postura de Varenio favorable a las ideas del heliocentrismo, para dar la impresión de su negación.

En el último cuarto del siglo xvII, la Geografía General de Varenio fue traducida al francés (1681), inglés (1680); en el siglo XVIII, se edita en ruso (1718) por indicación del mismo zar Pedro I y posteriormente en una nueva edición de 1790; y se traduce al alemán (1750) y al holandés (1750) a partir de la traducción de una edición inglesa realizada por Dugdale y Shaw (1733), que respetaría los textos incorporados por Newton y Jurin en ediciones anteriores (Capel, 1980).

En España la obra de Varenio no tuvo eco ni en las décadas posteriores a su muerte ni en todo el siglo XVIII. Como señala Capel su condición de holandés y luterano y la aceptación del sistema copernicano, condenado en España por la Inquisición, no hacían factible la impresión de su obra en nuestro país. A ello se une, el atraso de la ciencia española en general y la inexistencia de una ciencia geográfica oficial durante el s. XVII, lo que explica que la Geografía General no se conociera en nuestro país ni en la época de su edición ni con posterioridad. De hecho, no se tiene constancia de una edición impresa en España de la obra de Varenio en su totalidad, ni en su edición inicial en latín ni mucho menos en castellano. Tan sólo se puede consultar la traducción parcial al castellano que se llevó a cabo en la edición de la Universitat de Barcelona (1974), a cargo del prof. Horacio Capel y que mereció reimpresión en 1980. En la segunda 
mitad del siglo XVII, la repercusión de las ideas sobre la geografía incluidas en la obra de Varenio tan sólo mereció cita, como señala Capel (1980) por parte de dos autores españoles: el Padre José Zaragoza en su Esphera en común Celeste y Terraquea (1675) y Pedro Hurtado de Mendoza en su Espejo Geográfico (1690). El primero muestra su conocimiento de la obra del Varenio al señalar la necesidad de una parte absoluta y otra respectiva para el estudio de la Tierra. E1 segundo cita explícitamente en dos ocasiones a Varenio al referirse al problema del límite geográfico de América septentrional y de la formación de Gibraltar. En el siglo XVIII la obra de Varenio es citada en el trabajo de Tomás López, Principios Geográficos aplicados al uso de los mapas (1775-83), en concreto al hablar de los «klimata» y la duración de los días en diferentes lugares de la Tierra, así como al referirse a los vientos y a los problemas de navegación (Capel, 1980). Resulta curioso comprobar que en obras de contenido geográfico elaboradas por autores de repercusión en la España del siglo XVIII no mencionan en ningún momento el trabajo de Varenio, movidos, sin duda, por las cuestiones religiosas y de rechazo a las ideas copernicadas, señaladas. Es el caso de la España Sagrada del Padre Flórez y del Compendio Mathematico del Padre Tosca; en este segundo, es todavía más grave, como señala Capel (1980) porque la estructura y algunas partes de su obra dedicadas a las cuestiones geográficas, a los meteoros o a la navegación parecen extraídas, directamente, de la obra de Varenio sin citarlo en ningún caso.

En contraste con lo que ocurría en España, en los círculos científicos europeos sí se conocía y valoraba la Geografía General de Varenio y se cita como referencia en trabajos publicados en la segunda mitad del siglo XVII que abordan las cuestiones tratadas en la obra. Es el caso de Edmund Halley, quien en su ensayo sobre los vientos alisios y los monzones de 1686, se refiere al intento de explicación del funcionamiento de los vientos regulares (alisios y monzones) que incluye Varenio en la Geografia General (cap. XXI) señalando que contiene algunos errores que el físico británico intenta enmendar en su trabajo, a partir de información obtenida de viajeros y de su propia vivencia en el ámbito intertropical ${ }^{17}$ : «Varenio seems to have endeavoured after the best information from voyagers, yet cannot his accounts be admitted for accurate, by those that shall attentively consider and compare them together; and some of them are most evident mistakes; which, as near as I can, i shall attempt to rectify, having had the opportunity of conversing with navigators acquainted with all part of India, and having lived a considerable time between the tropics, and there made my own remarks.» (Halley, 1686, p. 153).

Newton sintió atracción por la Geografia de Varenio desde que tuvo conocimiento de su existencia. La primera edición de la Geografia General

17. Edmund Halley vivió en la isla de Santa Elena, entre 1676 y 1678. 
(Ámsterdam, 1650) tuvo amplia difusión en Inglaterra. Warntz (1989) señala que la introducción de esta obra en los estudios de la Universidad de Cambridge por parte de Isaac Barrow, primer Profesor Lucasiano ${ }^{18}$ de Matemáticas y Filosofía Natural en dicha universidad, resultó decisivo para el conocimiento de la obra de Varenio (Weinberg, 2015). En efecto, en los estatutos de esta figura académica se señalaba como deber de tal profesor la impartición de una lección, al menos una vez a la semana y durante un semestre, con contenidos de geometría, aritmética, astronomía, geografía, óptica, estática, o de cualquier otra materia matemática. De manera que la geografía se integraba como disciplina importante en el campo del saber universitario. Las anotaciones y documentos docentes de Isaac Barrow permiten concluir que él impartió lecciones de geografía en la Universidad de Cambridge mientras ocupó este puesto académico. Newton sucedió en el cargo a Barrow en octubre de 1670 pero, por el contrario, no hay constancia cierta de que impartiese clases de geografía en su labor docente en su condición de «Profesor Lucasiano». No obstante, debió ser destacada su afición a las materias geográficas si tenemos en cuenta que llevo a cabo una edición, con comentarios y datos añadidos propios, en 1672 en la propia Universidad de Cambridge, que mereció nueva reimpresión en 1681 (vid. Figura 3). Una evidencia de que esta edición de la Geografia General de Varenio, preparada por Isaac Newton en 1672, tuvo amplio eco entre los estudiantes de la universidad de Cambridge en esos años, se encuentra en el prefacio de la edición de la Geografía General preparada por Dugdale y Shaw en 1733, donde se señala, claramente, que «El original de esta obra fue reimpreso en Cambridge en el año 1672 para el uso de los estudiantes en esta Universidad...fue cuidadosamente corregida, en muchas partes ampliada y mejorada y las tablas y esquemas necesarios sustituidos por el Ilustrísimo Sir Isaac Newton, en su época de Profesor Lucasiano de Matemáticas en dicha Universidad», y añaden Dugdale y Shaw en dicho prólogo, «la razón por la cual este gran hombre-Newton- tuvo mucho cuidado en corregir y publicar a nuestro autor-Varenio- se debió a que lo estimó necesaria para ser leída por su público, los jóvenes caballeros -alumnos- de Cambridge, mientras él impartió Lecciones sobre esta materia desde la cátedra Lucasiana». El interés de Newton por la obra de Varenio tiene que ver con el propio concepto matemático de geografía que Varenio defiende en su trabajo:

18. El cargo de profesor Lucasiano de la Universidad de Cambridge, uno de los más relevantes de la academia universitaria en todo el mundo, fue fundado en 1663 por Henry Lucas, miembro del parlamento inglés por la Universidad entre 1639 y 1640 , y establecida oficialmente por Carlos II en 1664. Henry Lucas estableció en su testamento la cesión de su biblioteca de 4000 volúmenes a la Universidad y mandó la compra de terrenos que diesen un rendimiento anual de 100 libras para poder fundar una Cátedra; estableció asimismo que el profesor que ocupase esta cátedra tenía que dar por lo menos una clase de matemáticas a la semana y habría de estar disponible dos horas semanales para resolver las dudas de los alumnos. Isaac Newton sucedió, en 1670, a Barrow en este cargo. 


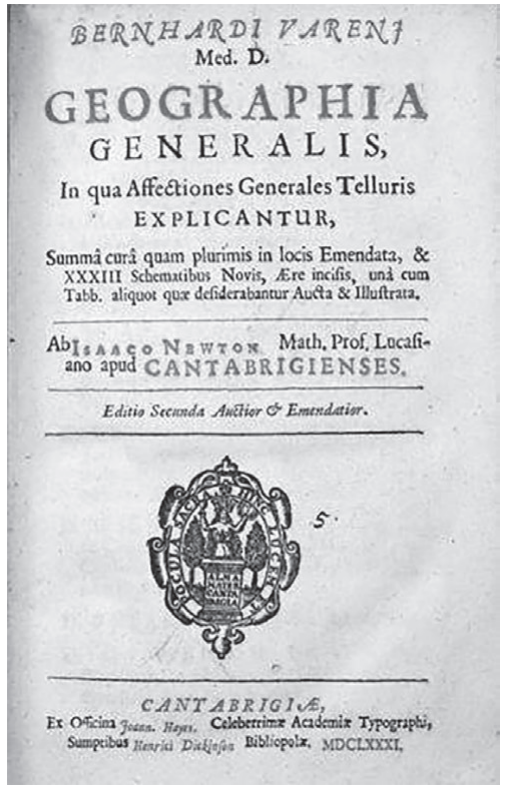

Figura 3: Portada de la edición de la Geografía General de Varenio de 1681, llevada a cabo por Isaac Newton, Profesor Lucasiano de la Universidad de Cambridge (Tomado de: www. vialibri.net).
«Geografia se llama la ciencia matemática mixta que explica las propiedades de la Tierra y de sus partes relativas a la cantidad, esto es, la figura, situación, dimensiones, movimientos, fenómenos celestes y otras propiedades similares» (Varenio, 1650, Sección Primera, Cap. I). Newton incluyó numerosos y sustanciales comentarios en las ediciones preparadas por él de la obra de Varenio, como figuras y esquemas para determinar el tamaño de la Tierra, para la estimación del grado de latitud, para el cálculo de las mareas, para la construcción de aparataje meteorológico, tablas con altitudes de montañas, con latitud y longitud de lugares importantes y con la descripción de los vientos y su comparación con las clasificaciones de este elemento climático realizadas por Seneca y Vitrubio.

Con posterioridad, discípulos y seguidores de las ideas de Newton (Roger Cotes, James Jurin), llevarían a cabo nuevas ediciones de la Geografía General para ir adaptando la obra a los nuevos descubrimientos y mejoras en la interpretación de los fenómenos de la naturaleza que iban apareciendo en el tránsito de los siglos XVII a XVIII. Es interesante señalar que en la edición de 1712 se citan, como nuevas referencias, trabajos realizados por físicos de la época que resultarán decisivos en la evolución de la meteorología y climatología; es el caso de Edmund Halley o de Evangelista Torricelli. Ello permitirá incluir novedades relacionadas con las disciplinas del tiempo atmosférico en dicha edición; en concreto, se incluyen referencias a las ideas de Halley sobre la circulación de los vientos alisios, publicadas en su famoso trabajo de 1686 (vid. supra), o a los trabajos de Torricelli sobre presión atmosférica y construcción del barómetro.

Kant, en su Geografía Física, tuvo en la obra de Varenio una referencia principal para el desarrollo de sus contenidos. En realidad, la propia estructura de la Geografía Física de Kant sigue una distribución temática similar a la Geografia de Varenio (vid. tabla adjunta) y puede llegar a parecer una síntesis de la magna obra de Varenio en las cuestiones de geografía general. Además, la división en 3 partes en que se organiza la Geografía Física de Kant corresponde a la división 
de la disciplina geográfica establecida por Varenio en su Geographía Generalis (cap. I), esto es:

- Geografía General, con exposición de la forma, figura, tamaño y divisiones de la Tierra, que vendría a ser una geografía geométrica al modo establecido desde época griega (Parte Primera de la Geografía Física de Kant)

- Geografía Respectiva, con explicación de los accidentes y observaciones de lo que contiene la Tierra a modo de «geografía física o naturalista» propiamente dicha. (Parte Segunda de la Geografía Física de Kant)

- Geografía Comparativa, que correspondería con lo que sería una geografía regional (Parte Tercera de la Geografía Física de Kant).

Como se ha señalado, Varenio desarrolló la parte general en su obra geográfica, pero no las otras dos y es en aquélla donde se encuentran paralelismos en la distribución temática de los contenidos tratados por Kant, que vienen a ser, en muchos casos, una síntesis de los apartados sobre estas cuestiones generales de la Geografía, incluidos en la Geographía Generalis de Varenio. Hay, sin embargo, un extenso apartado sobre «geografía matemática», donde Varenio aborda la descripción detallada de los conceptos de latitud, longitud, zonas y klimatas, así como la representación cartográfica de la superficie terrestre, que Kant no trata en su Geografía Física (vid. Tabla 2).

Tabla 2. Estructura de los grandes temas tratados por Varenio y Kant en sus tratados sobre geografía

\begin{tabular}{|c|c|c|}
\hline & $\begin{array}{l}\text { GEOGRAPHÍA GENERALIS (1650). } \\
\text { Bernhardus Varenius }\end{array}$ & $\begin{array}{l}\text { GEOGRAFÍA FÍSICA (1802). } \\
\text { Inmmanuel Kant }\end{array}$ \\
\hline \multirow{7}{*}{$\begin{array}{l}\text { Parte Primera } \\
\text { (Geografía } \\
\text { «absoluta» } \\
\text { según la } \\
\text { división de } \\
\text { Varenio) }\end{array}$} & Cap. I & - Introducción: concepto geografía \\
\hline & Caps. II, III, IV, V, VI, VI, VII & - Conceptos matemáticos previos \\
\hline & $\begin{array}{l}\text { Caps. XII, XIII, XIV, XV, XVI, } \\
\text { XVII, XVIII }\end{array}$ & $\begin{array}{l}\text { - Elementos principales de la } \\
\text { naturaleza } \\
\text { - Agua }\end{array}$ \\
\hline & Caps. VII, VIII, IX, X, XI & - Tierra \\
\hline & Caps. XIX, XX, XXI & -Atmósfera \\
\hline & No se incluye en la obra de Varenio. & $\begin{array}{l}\text { - Historia de los grandes cambios } \\
\text { ocurridos en la Tierra y de los que } \\
\text { están ocurriendo }\end{array}$ \\
\hline & $\begin{array}{l}\text { Caps. XXXV, } \\
\text { XXXVI,XXXVII,XVIII,XXXIX, } \\
\text { XL }\end{array}$ & -ANEXO: Sobre la navegación \\
\hline
\end{tabular}

Elaboración propia. 
Pero, sin duda, el gran descubridor de la obra de Varenio será A. von Humboldt en la primera mitad del siglo xix. Humboldt conocía la Geografía General de Varenio que consideraba una de las grandes obras para el conocimiento de la superficie terrestre y, aún más, para el desarrollo de su programa sobre una «Física del Globo». En el prólogo del Cosmos (1845-1862), al reflexionar sobre el contenido de su obra y la importancia que en élla debía tener la parte «celeste» y la «terrestre» en un tratado sobre la «física del Globo», señala Humboldt que «si a pesar de la pequeñez de nuestro planeta, lo que le concierne exclusivamente ocupa en esta obra el lugar más importante, y se encuentra desarrollado con mayor precisión, depende esto únicamente de la desproporción de nuestros conocimientos entre lo que es asequible a la observación y lo que de ella escapa. Esta subordinación de la parte celeste a la terrestre, se encuentra ya en la gran obra de Bernardo Varenio, que apareció a mediados del siglo XVII. Fue el primero que distinguió la geografía general y la geografía especial, subdividiendo la primera en geografía absoluta, es decir, propiamente terrestre, y en geografía relativa o planetaria, según que se mire a la superficie de la tierra en sus diferentes zonas, o las relaciones de nuestro planeta con el sol y la luna. Es un justo título de gloria para Varenio, que su Geografia general y comparada pudiera fijar, como fijó, en alto grado la atención de Newton. Según el imperfecto estado de las ciencias auxiliares de que debía valerse, el resultado no podía corresponder a la magnitud de la empresa. Estaba reservado a nuestro tiempo, y a mi patria, ver trazar a Carlos Ritter el cuadro de la geografía comparada en toda su extensión, y en su íntima relación con la historia del hombre.» ${ }^{19}$. Humboldt añade que «desde la descripción del Nuevo Continente, discretamente bosquejada por el jesuita José de Acosta (Historia natural de las Indias, 1590), no habían sido consideradas de una manera tan general las cuestiones que se relacionan con la física del globo. Acosta es más rico en observaciones, pero Varenio abraza un círculo de ideas más extenso, porque su permanencia en Holanda, centro de las más vastas relaciones comerciales de la época, le había puesto en contacto con gran número de viajeros instruidos» ${ }^{20}$.

Por último, junto a valoración de las aportaciones de la obra de Varenio a diferentes disciplinas científicas, entre ellas la Geografía, un aspecto muy desconocido hasta fecha reciente fue el propio recorrido biográfico del autor alemán. A finales del siglo XIX, el geógrafo y director de la Escuela Marítima de Bremen, Arthur Breusing, rescató la memoria de Varenio en un conocido trabajo

19. Vid. Humboldt. A. de: Cosmos. Ensayo de una descripción física del mundo. Vertido al castellano por Bernardo Giner y José de Fuentes, Madrid, Imprenta de Gaspar y Roig, Editores, 4 tomos, 1874-1875. Introducción («Límites y métodos de exposición de la descripción física del mundo», Tomo I (1874, págs. 39-62). El texto que se reproduce está tomado de las págs. 50 y 51 de dicha Introducción.

20. Humboldt, A. de. Op.cit 19. p.356. 
biográfico sobre el geógrafo alemán ${ }^{21}$. En 1905, Siegmund Günter publicó en Leipzig $^{22}$ un estudio detallado con los trabajos sobre Varenio elaborado por investigadores alemanes y holandeses que será la obra de referencia sobre la vida y obra de Varenio hasta bien entrado el siglo xxI. De Jesús y Schubring (2008) señalan que un trabajo fundamental para el conocimiento de la vida de Varenio, pero prácticamente desconocido, fue la recopilación de documentos y notas biográficas recogidos por Carl Rorbach, director de una escuela secundaria (Realschule) en Gotha (Thüringen). Sus trabajos sobre Varenio permanecieron desconocidos, no siendo publicados hasta después de que los herederos y descendientes de Rohrbach vendieran en el año 2000 el fondo documental sobre Varenio a la Landes-bibliothek Eutin. En 2001, esta biblioteca organizó una exposición del material y publicó un libro con los primeros análisis de las nuevas evidencias, sacadas de las notas de Rohrbach.

Este fondo documental renovó el interés por la vida y obra de Varenio. En 2004, la Margret Schuchard, de la Universidad de Heidelberg, organizó un encuentro internacional para evaluar este material expuesto en 2001 sobre Varenio y publicó un estudio -el último editado sobre el geógrafo alemán- con nuevas contribuciones sobre su vida y obra, así como una valoración crítica sobre su influencia para la difusión de la disciplina geográfica en diferentes países (Estados Unidos, Rusia) ${ }^{23}$.

\section{BiBLIOGRAFÍA}

Alberola Romá, A. (2014) Los cambios climáticos. La Pequeña Edad del Hielo en España, Madrid, Ed. Cátedra, 341 p.

Arcimis, A. (1902) Meteorología. Barcelona, Manuales Soler n. ${ }^{\circ}$ XVIII, 198 p.

Arnau, J. (2014) Manual de filosofía portátil. Madrid. Ediciones Atalanta, 566 p.

Barry, R. G. and Chorley, R. J. (1999) Atmosphere, Weather and Climate. (7.a ed.), London and New York, Ed. Routledge, $441 \mathrm{p}$.

Belaval, Y. von. (dir.) (1982) La filosofia alemana, de Leibniz a Hegel. Historia de la Filosofía. Mexico, Ed. Siglo XXI, 459 p.

Brazdil, R.Ch.; Pfister Ch., Wanner H., Von Storch, H. and Luterbacher, J. (2005) «Historical climatology in Europe. The state of the art», Climate Change $70,363-430$.

CAPEL, H. (1980) «Estudio preliminar», en Geografia General en la que se explican las propiedades generales de la Tierra (Bernhard Varenio). Ediciones de la Universidad de Barcelona, pp. 11-84.

21. Vid. Lebensnachrichten von Bernhard Varenius. Dr. A. Petermann's Mittheilungen aus Justus Perthes' Geographischer Anstalt 26 (1880), S. 136-145

22. Vid. Günther, S. (1905) Varenius, Ed. Thomas, serie Klassiker der Naturwissenschaften 4, Leipzig, $218 \mathrm{p}$.

23. Vid. Schuchard, M. (ed.) (2008) Bernhard Varenius (1622-1650). Ed. Brill, Leiden, 346 p. 
Capel, H. (2012) Filosofía y Ciencia en la Geografia contemporánea. Barcelona, Ediciones del Serbal, $480 \mathrm{p}$.

Cohen-Halimi, M. (1999) «Le Géographe de Königsberg». In: KANT, Immanuel. Géographie. Physische Geographie. Paris, Aubier, p. 9-40.

Copleston, F. (2011) Historia de la Filosofia. Vol. 3. (De la Filosofía Kantiana al Idealismo). Barcelona, Ed. Ariel. Col. Filosofía, 752 p.

Chambers, E. (1728) Cyclopaedia: Universal Dictionary of Arts and Sciences. Londres. (voz. «Trade-winds») (on-line: www.cyclopaedia.eu). Consultado: agosto 2014.

De Jesús Brito, A. y Schubring, G. (2008) «La práctica de la matemática «normal» en el siglo XVII: el caso de la Geografía Matemática de Varenius», rev. Llull, vol. 31, 41-60.

Delgado Castillo, R. y Francisco Arturo Ruiz Martínez, F. A. «Revolución de la física y su impacto en las ciencias del siglo XVII», On-line. Disponible en http://www. galeon.com/histofis/7REV1F.htm. Consultado en: mayo 2015.

Descartes, R (2007). Discurso del método. Madrid. Ed. Akal, 96 p.

Elden, S. (2008) «Reassessing Kant's geography». Journal of Historical Geography (doi: 10.1016/j.jhg.2008.06.001).

Elden, S. (2011) Reintroducing Kant's geography. Albany, State University of New York Press, $15 \mathrm{p}$.

ELDEN, S. (2013) «Leibniz and geography: geologist, paleontologist, biologist, historian, political theorist and geopolitician», Geographica Helvetica, 68, 81-93.

De Martonne, E. (1964) Tratado de Geografía Física. Tomo I. Nociones Generales, Clima, Hidrología, (ed. en español), Barcelona, Ed. Juventud, 520 p.

Flammarion, C. (1875) La atmósfera: descripción de los grandes fenómenos de la naturaleza. (trad. Luis Barinaga y Corradi). Madrid, Imprenta y Librería de Gaspar, Editores, $428 \mathrm{p}$.

Gil Olcina, A. y Olcina Cantos, J. (1997) Climatología general. Barcelona, Ed. Ariel. Col. Geografía, 592 p.

Glacken, C. J. (1996) Huellas en la playa de Rodas. Barcelona, Ed. del Serbal, 729 p.

Halley, E. (1686) «An Historial Account of the Trade Winds, and Monsoons, observable in the Seas between an $\mathrm{d}$ near the Tropicks, with an attempt to assing the phisical cause of the said winds», Philosophical Transactions, n. $^{\circ} 183$, pp. 153-168.

Hadley, G. (1735) «Concerning the cause of the general trade-winds», Phil. Trans. 39, 1735-1736, published 1 January 1735. (Ed. Royal Society, on line). En línea: consultado agosto 2014.

Humboldt, A. v. (1944) Cosmos. Ensayo de una descripción física del mundo. Buenos Aires. Ed. Glem, 601 p.

Kant, I. (1981) Filosofía de la Historia. México, Fondo de Cultura Económica, 151 p.

Kunzmann, P., Burkard, F.P. y Wiedmann, F. (1977) Atlas de filosofía. Alianza Editorial, Madrid, 249 p.

Lorente, J.M. (1930) Meteorología. Barcelona, Editorial Labor, 192 p.

MAnzo, S. (2004) «Francis Bacon y la concepción aristotélica del movimiento en los siglos XVI y XVII», Revista de Filosofía, vol. 29, num. 1, 77-97. 
Medina Isabel, M. (1976) Meteorología básica sinóptica. Madrid, Ed. Paraninfo, 320 p.

Olcina CANTOS, J. (2013) «Clasificación de las nubes: de Lamarck y Howard al Atlas Internacional de Nubes», en Clima, Naturaleza y desastre. España e Hispanoamérica durante la Edad Moderna (Alberola Romá, A., coord.), Valencia, Publicacions de la Universitat de València, pp. 193-224.

Olcina CANTOS, J. (2014) «Referencias atmosféricas y avances para la ciencia climática en la obra de José de Acosta». Scripta Nova. Revista Electrónica de Geografía y Ciencias Sociales. [En línea]. Barcelona: Universidad de Barcelona, vol. XVIII, n. ${ }^{\circ}$ 478. <http://www.ub.es/geocrit/sn/sn-478.htm>.

Ortega Valcarcel, J. (2000) Los horizontes de la geografía. Teoría de la geografía. Barcelona, Ed. Ariel. Col. Geografía., 604 p.

Pedroso BAUAB, F. () «Aspectos precursores da geografia moderna na obra Geografia Geral (1650), de Varenius» (1621/1662-1650)», Observatorio Geográfico de America Latina, on line. Disponible en http://observatoriogeograficoamericalatina. org.mx/egal12/Teoriaymetodo/Pensamientogeografico/18.pdf. Consultado: mayo 2015.

PelkowsKi, J. (2004) «La anemología kantiana: context histórico y versión castellana», Revista del Aficionado a la Meteorología (RAM). On line. Disponible en: http:// www.tiempo.com/ram/33112/la-anemologia-kantiana-contexto-historico-y-version-castellana/. Consultado: mayo 2015.

Pelkowski, J. (2005) «El certamen de 1746 acerca de la causa de los vientos generales», Meteorología Colombiana, n. ${ }^{\circ} 9$.

Pelkowski, J. (2006-2007) «Teoría de los Alisios durante la Ilustración (I y II)», en Boletín de la Asociación Meteorológica Española (5. etapa) n. ${ }^{\circ} 14$ y 15 . Madrid.

Persson, A.O. (2006) «Hadley's Principle: Understanding and Misunderstanding the Trade Winds», History of Meteorology, 3, pp. 17-42.

Rевок, S. (2008) «The influence of Bernhard Varenius in the geographical works of Thomas Jefferson and Alexander von Humboldt» in Bernhard Varenius (16221650), Ed. Brill, p. 259-270.

Redondo Álvaro, F. L. (2009) «Algunos rasgos de la revolución científica en el siglo XVII», Boletín. Instituto de Estudios Giennenses, 198, 565-599.

Refolio Refolio, M. a C. y LóPez SANChO, J. M. a (2011) «Un mapa cultural para situar la enseñanza de la ciencia: la revolución científica y el fin del aristotelismo», Digital CSIC, on line: Disponible en: http://digital.csic.es/handle/10261/83293. Consultado en: mayo 2015.

Reguera Rodríguez, A. T. (2001-2002) «Newton y Feijoo. Un episodio en la historia de la difusión de las ideas científicas (I y II)», en Contextos XIX-XX, n. ${ }^{\circ}$ 37-40 (2001-2002), on line. Disponible en: https://buleria.unileon.es/handle/10612/405. Consultado en: mayo 2015.

Rojas Salazar, T. (2007) «Los aportes de Kant a la geografía». Rev. Terra, vol. XXIII, n. ${ }^{\circ} 34,11-33$.

Russell, B. (2010) Historia de la Filosofía Occidental. Tomo II (La filosofía moderna). Madrid, Ed. Austral, 550 p. 
SCHUCHARD, M. (2007 a) «The road to authorship and publications: projects, patronage and the Elzeviers», in Bernhard Varenius (1622-1650), (Edited by Margret Schuchard), Brill Academic Publishers, p. 91-98

Schuchard, M. (2007 b) «Notes On Geographia Generalis And Its Introduction To England And North America», in Bernhard Varenius (1622-1650), (Edited by Margret Schuchard), Brill Academic Publishers, p. 227-238.

SutTon, G. (1960) «Theories of the circulation of the earth's atmosphere», The Observatory, vol. 80, n. ${ }^{\circ}$ 918, 169-190.

Uriarte, A. (2002) Historia del Clima de la Tierra. Vitoria, Servicio Central de Publicaciones del Gobierno Vasco, $306 \mathrm{p}$.

Urteaga, L. (1993) «La teoría de los climas y los orígenes del ambientalismo», Geocrítica, año XVIII, n. ${ }^{\circ}$ 99, Universidad de Barcelona. Disponible en http:// www.ub.edu/geocrit/geo99.htm (Consultada en agosto de 2014).

VARENIO, B, (1664) Geographia generalis, in qua affectiones generales telluris explicantur. Amstelodami, Ex Officina Elzeviriana, 748 p.

VARENIO, B. (1974) Geografia General, en la que se explican las propiedades generales dela Tierra, (Edición y estudio preliminar de Horacio Capel), Barcelona. Ediciones de la Universidad de Barcelona, 147 p.

VermiJ, R. (2007) «Varenius and the world of learning in the Dutch Republic» in Bernhard Varenius (1622-1650), (Edited by Margret Schuchard), Brill Academic Publishers, p. 99-116.

ViCUÑA, Gumersindo. (1880) Manual de meteorología popular, Madrid, Biblioteca Enciclopédica Popular Ilustrada, $232 \mathrm{p}$.

WARnTZ, W (1989) «Newton, Then Newtonians, and the Geographia Generalis Vareniì, Annals of the Asociation of American Geographers, 79 (2), 165-191.

WATkIns, E. (edit.) (2012) Natural Science. The Cambridge edition of the Works of Immanuel Kant in translation. San Diego, University of California, 818 p.

WeInBerg, S. (2015) Explicar el mundo. El descubrimiento de la ciencia moderna. Madrid. Ed. Taurus, 432 p. 